UC-25 - Metals, Ceramics, and Materials

\title{
DETERMINATIONS OF THE KINETICS AND
}

MECHANISMS OF DEBORONIZATION AT $1135^{\circ} \mathrm{C}$

J. H. Cherubini

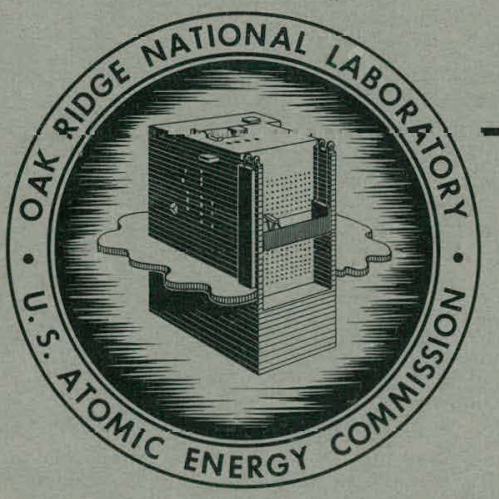

OAK RIDGE NATIONAL LABORATORY

$$
\text { operated by }
$$

UNION CARBIDE CORPORATION

for the

U.S. ATOMIC ENERGY COMMISSION 


\section{DISCLAIMER}

This report was prepared as an account of work sponsored by an agency of the United States Government. Neither the United States Government nor any agency Thereof, nor any of their employees, makes any warranty, express or implied, or assumes any legal liability or responsibility for the accuracy, completeness, or usefulness of any information, apparatus, product, or process disclosed, or represents that its use would not infringe privately owned rights. Reference herein to any specific commercial product, process, or service by trade name, trademark, manufacturer, or otherwise does not necessarily constitute or imply its endorsement, recommendation, or favoring by the United States Government or any agency thereof. The views and opinions of authors expressed herein do not necessarily state or reflect those of the United States Government or any agency thereof. 


\section{DISCLAIMER}

Portions of this document may be illegible in electronic image products. Images are produced from the best available original document. 
Printed in USA. Price $\$ 2.25$. Available from the

Office of Technical Services

Department of Commerce

Washington 25, D.C.

\section{LEGAL NOTICE}

This report was prepared as an account of Government sponsored work. Neither the United States, nor the Commission, nor any person acting on behalf of the Commission:

A. Makes any warranty or representation, expressed or implied, with respect to the accuracy, completeness, or usefulness of the information contained in this report, or that the use of any information, apparatus, method, or process disclosed in this report may not infringe privately owned rights; or

B. Assumes any liabilities with respect to the use of, or for damages resulting from the use of any information, apparatus, method, or process disclosed in this report.

As used in the above, "person acting on behalf of the Commission" includes any employee or contractor of the Commission, or employee of such contractor, to the extent that such employee or contractor of the Commission, or employee of such contractor prepares, disseminates, or provides access to, any information pursuant to his employment or contract with the Commission, or his employment with such contractor. 
ORNL-314I

UC-25 - Metals, Ceramics, and Materials TID-4500 (16th ed. )

Contract No. W-7405-eng-26

METALLURGY DIVISION

DETERMINATIONS OF THE KINETICS AND MECHANISMS

OF DEBORONIZATION AT $1135^{\circ} \mathrm{C}$

Julian H. Cherubini

Submitted as a thesis to the Graduate Council of the University of Tennessee in partial fulfillment of the requirements for the degree of Master of Science

\author{
DATE ISSUED
}

\title{
SEP 151961
}

OAK RIDGE NATIONAL LABORATORY

Oak Ridge, Tennessee

operated by

UNION CARBIDE CORPORATION

for the

U. S. ATOMIC ENERGY COMMISSION 
THIS PAGE

WAS INTENTIONALLY

LEFT BLANK 


\section{ACKNOWLEDGMENT}

The author wishes to express his sincere indebtedness to Dr. E. E. Stansbury for his illuminating guidance throughout the preparatory and experimental portions of this investigation and constructive criticisms during the manuscript preparation.

Although it would be impossible to acknowledge everyone contributing to this work, the author wishes to proffer special thanks to these members of the Oak Ridge National Laboratory staff: R. I. Beaver for hid addiatance and coopcration in expediting this investigation; W. R. Laing and R. M. Hill, Jr., who developed and applied many of the analytical techniqucs cmployed; R. J. Gray and R. S. Crouse for their advice on metallographic specimen preparation; W. Colwell for his aid in illustrations; and J. E. Cunningham for his critical review of the final manuscript. To those unnamed, thank you.

Those laboratory personnel who were of direct assistance in accumulating the necessary experimental data for this study include J. W. Geer, compact fabrication and heat treatment; B. Philpot, J. Hill, G. Brown, and J. Botts, chemical analysis; and R. J. Lockett, metallography: Their contributions are gratefully appreciated. 
The author is indebted to Mr. Geneva Harris and Mrs. Freda Finn of the Metallurgy Division for their cooperation by typing this manuscript and to Mrs. Meredith R. Hill for her assistance in expediting the preparation of this manuscript.

Appreciation is also extended to the Union Carbide Nuclear Company for its employee educational assistance program and to the Army Power Branch for program financing. 
TABLE OF CONTENTS

CHAPTER

PAGE

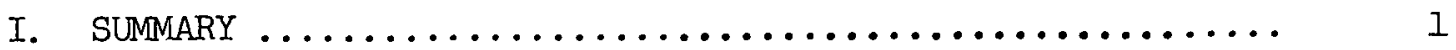

II. INTRODUCTION $\ldots \ldots \ldots \ldots \ldots \ldots \ldots \ldots \ldots \ldots \ldots \ldots \ldots \ldots \ldots \ldots . \ldots \ldots$

III. SURVEY OF PRTOR WORK $\ldots \ldots \ldots \ldots \ldots \ldots \ldots \ldots \ldots \ldots \ldots \ldots \ldots \ldots$

Material System.$\ldots \ldots \ldots \ldots \ldots \ldots \ldots \ldots \ldots \ldots \ldots \ldots \ldots \ldots$

Deboronization Observations and Reactions .......... 7

IV. EXPERTMENTAL PROCEDURE ...................... 22

Qualitative study of Hnvironmential Ettectis .......... ¿'

Kinetics of Boron Loss from Boron-Stainless Steel

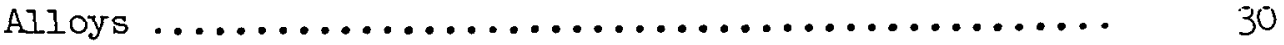

V. RESULTS AND DISCUSSION ..................... 36

Qualitative Determination of the Mechanism of Boron

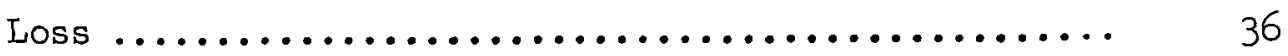

Examination of Deboronization Kinetics ............ 54

Deboronization of Sheet Specimens ............... 66

VI. CONCLUSIONS $\ldots \ldots \ldots \ldots \ldots \ldots \ldots \ldots \ldots \ldots \ldots \ldots \ldots \ldots \ldots . \ldots \ldots$

Boron Loss from Powder Compacts Containing Five Weight

Per Cent Boron Heat Treated at $1135^{\circ} \mathrm{C} \ldots \ldots \ldots \ldots . \ldots 2$

Boron Loss from Boron-Stainless Steel Alloys ......... 83

APPENDIX $I \ldots \ldots \ldots \ldots \ldots \ldots \ldots \ldots \ldots \ldots \ldots \ldots \ldots \ldots \ldots \ldots \ldots \ldots$

AFFENDIX II $\ldots \ldots \ldots \ldots \ldots \ldots \ldots \ldots \ldots \ldots \ldots \ldots \ldots \ldots \ldots \ldots \ldots$

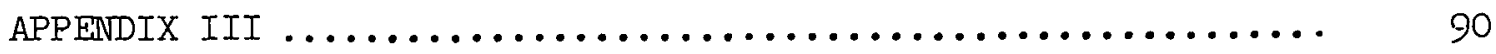

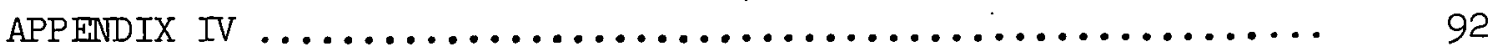

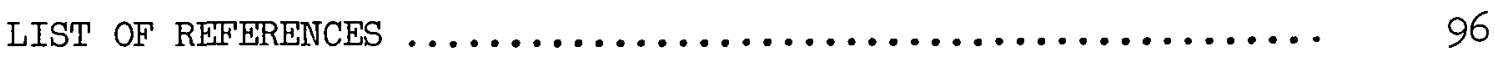


CHAPTER I

\section{SUMMARY}

The mechanisms and kinetics of the loss of boron during heating at $1135^{\circ} \mathrm{C}$ under various dynamic environments were determined from (1) powder compacts of 5 weight per cent elemental boron dispersed in matrices of $\mathrm{Fe}, \mathrm{Cr}, \mathrm{Ni}, \mathrm{Si}, \mathrm{Fe}_{2} \mathrm{O}_{3}, \mathrm{Cr}_{2} \mathrm{O}_{3}, \mathrm{NiO}$, and $\mathrm{SiO}_{2}$, (2) compacts of austenitic stainless steel alloy powder containing 0.25 weight per cent boron, and (3) wrought specimens of 0.13 weight per cent boronstainless steel alloy.

The compacts containing 5 weight per cent boron were heat treated in vacuum, high-purity argon, wet helium, and hydrogen. With the exception of those heat treated in hydrogen, significant boron. losses occurred only when a supply of oxygen, either from the sample itself or as a deliberate addition to the heat-treating environment, was available. Correspondingly, the loss mechanism is postulated to be the oxidation of boron to boron sesquioxide and its volatilization from the sample. The loss rate is controlled by the volatilization rate of the oxide which is directly influenced by (1) structure of the compact and (2) sintering environment.

Independent of the chemical nature of the matrix, boron losses were incurred during heat treatment in hydrogen. Variations of the water content of the hydrogen from 7 to 460 parts per million did not significantly influence the total boron loss observed. The synthesis 
of boron and hydrogen into a gaseous boron-hydrogen species is postulated as a predominating loss mechanism in a hydrogen environment.

Compacts of austenitic stainless steel powder containing 0.25 weight per cent boron were heat treated at $1135^{\circ} \mathrm{C}$ from one-fourth to sixteen hours in hydrogen atmospheres of three different water vapor levels, 1, 100, and 460 parts per million. The losses observed in each environment for the first few hours of heat treatment followed the relationship:

$\Delta B=0.26 t^{1 / 2}+C$

where

$\triangle B$ is total boron loss in milligrams,

$t$ is total heat-treating time in hours, and

C is a constant.

However, the rate of boron loss of samples heated in the driest hydrogen decreased abruptly after two hours at temperature. Under the other environmental conditions, a similar decrease was observed after seven hours. The degree of sample sintering was found to be the predominating factor determining the boron loss rate.

The rate of decrease of total sample surface area by sintering was observed to have a proportional effect in decreasing the rate of buron loss. However, the rate-controlling step in the deboronization of master alloy compacts was the rate of diffusion of gaseous reactant in and reaction products out of the sample. This in turn was controlled by the effective diameter, length, and number of channels permeating the 
compact and exposed to the sintering environment. Consequently, the variation of the heat-treating conditions affects the total boron loss only as it influences the rate of compact sintering. However, the rate of deboronization of the wrought metal samples is controlled by the rate of solid-state diffusion of boron to the gas-metal interface, providing the heat-treating atmosphere can react with the boron at the interface so as to maintain a very low boron surface concentration. Deboronization of wrought specimens was observed in both hydrogen (less than 15 parts per million $\mathrm{H}_{2} \mathrm{O}$ ) and helium (15,000 parts per million $\mathrm{H}_{2} \mathrm{O}$ ). 
CHAPTER II

INTRODUCTION

A problem of considerable import which was recognized during the development of stainless steel-base, composite-type fuel plates for the Army Stationary Medium Power Reactor (SM-I), was the erratic and unpredictable loss of boron from the plates during their fabrication $(1,2)$. This investigation was initiated to (1) determine the mechanism of boron loss and (2) to define the associated rate-controlling process. It was anticipated that these would suggest methods to eliminate or to reliably predict the loss of boron during fuel component manufacture. Boron had been deliberately added to each fuel plate to compensate for a high uranium investment and thereby control the high initial reactivity of the reactor. Mandated by program schedule, the boron lost from the plates during fabrication was not accurately determined. However, a subsequent study revealed that the boron content per fuel' plate was reduced an average of 22 per cent as a result of plate processing (3).

To determine the chemical reaction involved in the loss, the roles of heat-treating atmosphere and sample composition were ascertained. Compacts of 5 per cent boron mechanically dispersed in selected metal and metal oxide matrices were heat treated at $1135^{\circ} \mathrm{C}$ for 75 minute's in various atmospheres, and the resulting boron loss analytically determined. The kinetics of the loss in a powder alloy 
system were investigated by heat treating compacts of 0.25 weight per cent boron-austenitic stainless steel alloy at $1135^{\circ} \mathrm{C}$, and determining the boron lost as a function of time and water vapor content in the atmosphere, hydrogen. Further, the solid-state diffusion aspects of the loss, which is analogous to losses incurred during fuel plate rolling and annealing or fuel element brazing, were determined by establishing the boron-loss characteristics of 0.12 weight per cent boron-stainless steel alloy heat treated at $1135^{\circ} \mathrm{C}$ in dry hydrogen. 
CHAPTER III

SURVEY OF PRIOR WORK

I. MATERIAL SYSTEM

Previous investigations of the boron-iron and boron-stainless steel systems have been concerned primarily with the very low boron content range of less than 0.001 per cent and the $0.5-3.0$ per cent range, respectively. Steels of low boron content have been of interest for they exhibit remarkably higher hardenability than their boron-free counterparts $(4,5,6)$. The $0.5-3.0$ per cent boron-stainless steel alloys have a high thermal-neutron cross section due to the presence of boron-10 and are of interest in. nuclear reactor control and shielding applications $(7,8,9,10)$. The distribution and form of boron in the low-boron steels are not conclusively known. However, the 0.5-3 per cent boron-stainless steel alloys are described as two-phase systems of a transitional metal boride, probably $(\mathrm{Fe}, \mathrm{Cr})_{2} \mathrm{~B}$, dispersed in a matrix of stainless steel (10).

The boron-iron phase diagram has been determined in the low boron range by Parke (11) and, more recently, by Busby et al. (12). If the same general high-temperature equilibrium relationships established by the latter are maintained when 18-8 type stainless steel is substituted for iron, the boron solid solubility at $1150^{\circ} \mathrm{C}$ is 0.024 weight per cent. Thus, the 0.13 and 0.25 weight per cent boronstainless steel alloys of interest in this investigation are expected 
to be two phase at the temperature of interest with a major portion of the boron occurring as $(\mathrm{Fe}, \mathrm{Cr})_{2} \mathrm{~B}$.

\section{DEBORONIZATION OBSERVATIONS AND REACTIONS}

The boronization of steel was observed as early as 1917 by Tschischewsky (13) who found that iron heated in contact with powdered boron acquired a hard boron-rich case. Later, Cambell and Fay (14) confirmed this observation and likened it to the carburization of steel. One of the first references concerning the deboronization process was by Diggs, Irish, and Canvile (15). They heated steel containing 0.0038 per cent boron in a decarburizing atmosphere (natural and manufactured gas plus air and water vapor) for eight hours at $1038^{\circ} \mathrm{C}$ and then determined the boron concentration gradient in the decarburized zone. A very high boron concentration was found at the gas-metal interface which was attributed to the accumulation of $\mathrm{B}_{2} \mathrm{O}_{3}$; directly below the metal surface, boron was not detectable. However, the boron concentration progressively increased with distance from the sample surface until it reached the initial boron concentration.

The first systematic and detailed investigation of the diffusion of boron in iron and steel was that reported by P. E. Busby et al. (12). Their dual objective included the determination of the diffusion coefficient and the solubility of boron in iron. A preponderance of their data was obtained by heat treating iron-boron ( 0.04 weight per cent boron maximum) alloys in hydrogen saturated with water vapor at $20^{\circ} \mathrm{C}$. 
They found that boron diffuses to the sample surface where it is oxidized to a stable boron oxide which accumulates and manifests itself as a relatively high concentration of boron at the metal-gas interface. Furthermore, directly beneath the metal surface, boron was not detected by spectrographic analysis. A typical deboronization eurve illustrating the variation of boron concentration with distance is shown in Figure 1. The break in the boron concentration-distance curve indicates that the solubility limit of boron in austenite is 0.009 per cent at the diffusion temperature, $1002^{\circ} \mathrm{C}$. By correlation of similar data, the investigators reported a diffusion coefficient for boron in austenite as $D_{\gamma}=2 \times 10^{-3} \exp [-21,000 / \mathrm{RT}]$.

Later work of Shyne and Morgan (16) qualitatively reconfirmed the deboronization behavior observed by others. Samples of iron-boroncarbon alloy, austenitized in a dynamic atmosphere of argon $(0.024$ weight per cent oxygen) for 30 minutes at $870^{\circ} \mathrm{C}$, were deboronized but not decarburized. Neither plating with copper prior to heat treatment, the usual method to prevent decarburization, nor decreasing the oxygen concentration of the argon to 0.0014 weight per cent prevented deboronization. Samples were also heat treated at $955^{\circ} \mathrm{C}$ for 80 minutes each in vacuum and buried in charcoal. As anticipated, deboronization. was not observed in the former although it was in the latter. The authors attributed the absence of deboronization during vacuum heat treatment to the very low oxygen partial pressure. 
UNCLASSIFIEO

ORNL-LR-OWG 51075

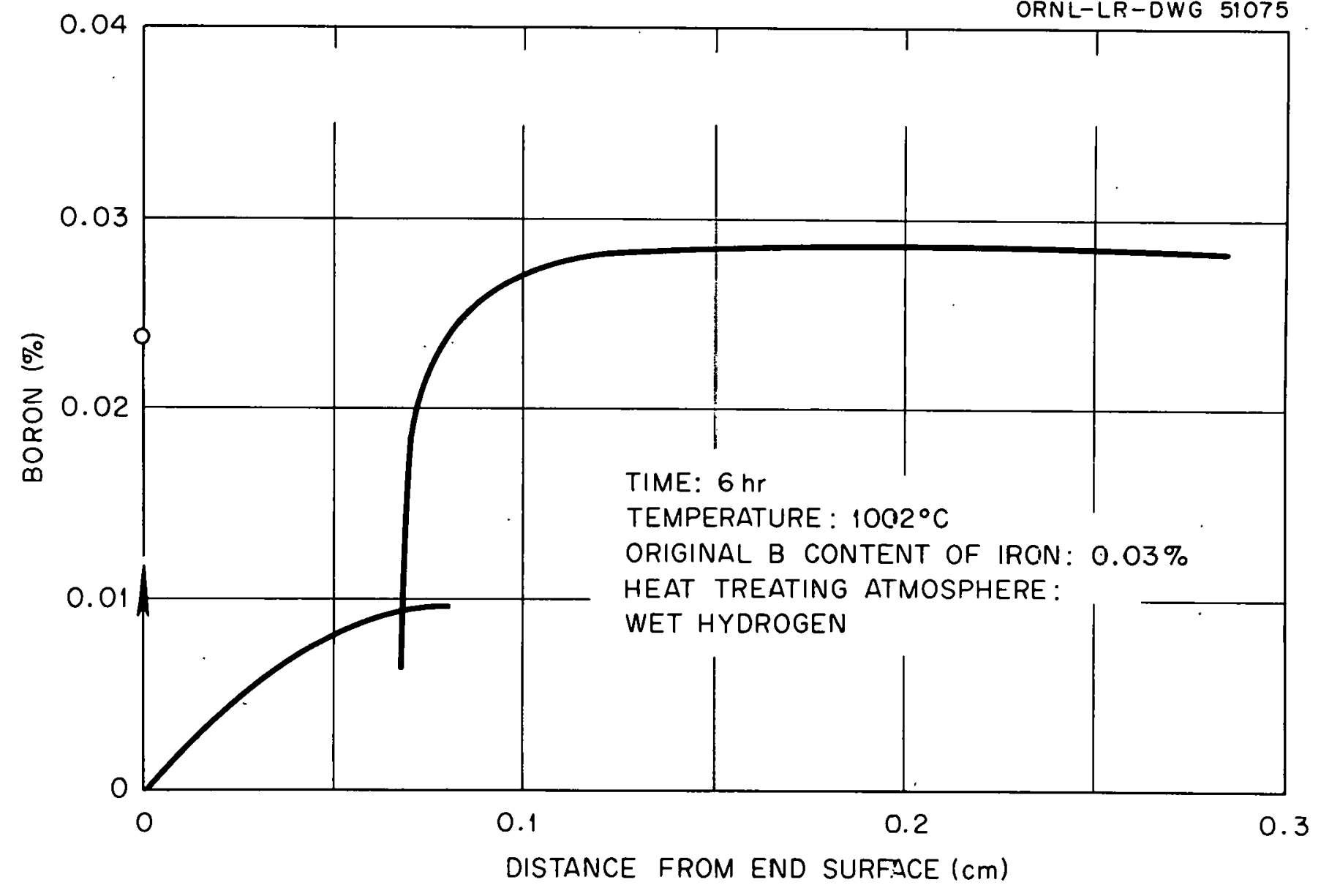

Figure 1. Concentration-distance curve demonstrating the deboronization of iron-boron alloys and indicating the solubility limit of boron in austenite to be approximately 0.009 weight per cent boron at $1002^{\circ} \mathrm{C}$.

[P. E. Busby, M. E. Warga, and $\lesssim$. Wells, "Diffusion and solubility of Boron in Iron and Steel," J. Metals, 1463-1468 (November, 1953). ] 
The calculated free-energy change of the reduction of the oxides of carbon by boron is negative at the temperatures of interest, as shown in Figure 2. Thus, deboronization in carburizing conditions is thermodynamically feasible. The reduction of water vapor by boron is possible as illustrated in Figures $3(a), 3(b)$, and 4. Likewise, the reduction of the common oxides of chromium, iron, silicon, and nickel to yield boron sesquioxide, and in the case of $\mathrm{Fe}_{2} \mathrm{O}_{3}$ and $\mathrm{NiO}$, boron monoxide is possible $(17,18)$. Thus, the oxidation of boron at the surtace of an iron-boron alloy specimen on heating at elevated temperatures in wet hydrogen is thermodynamically allowable, concurring with Busby's postulation (12). Presumably, in these cases, the Ioss of boron from the sample itself would result from the volatilization of the accumulated boron oxide.

The vapor pressure of boron sesquioxide has been reported (19) as $\log \mathrm{p}(\mathrm{atm})=6.742-\frac{16,960}{\mathrm{~T}}\left(1331<\mathrm{T}<1808^{\circ} \mathrm{K}\right)$.

This corresponds to a value of $2.4 \times 10^{-6}$ atmosphere at $1100^{\circ} \mathrm{C}$ and $6.9 \times 10^{-6}$ atmosphere at $1150^{\circ} \mathrm{C}$. The extrapolated value at $1000^{\circ} \mathrm{C}$ is $2.8 \times 10^{-7}$ atmosphere. Evans et al. (20) reports values which are in substantial agreement with the above. Further, H. F. Rizzo et al. (2I) observed that although the oxidation of boron could occur in air at temperatures below $1000^{\circ} \mathrm{C}$ the volatilization of $\mathrm{B}_{2} \mathrm{O}_{3}$ became significant only at higher temperatures.

Considering the low vapor pressure of $\mathrm{B}_{2} \mathrm{O}_{3}$ at $1000^{\circ} \mathrm{C}$ and, therefore, its implied low volatilization rate (22), it is not surprising 


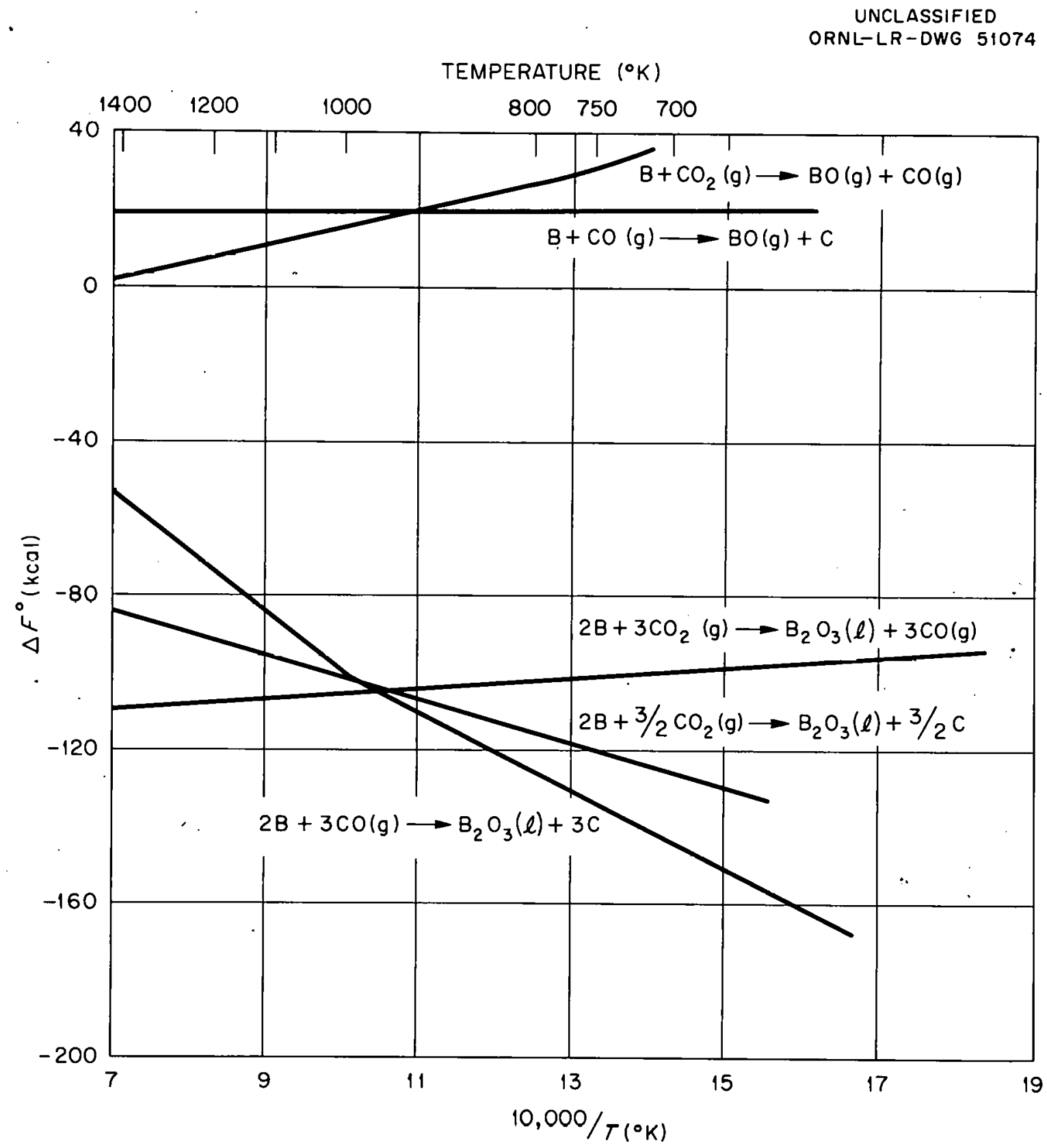

Figure 2. The standard free energy of formation, $\Delta F^{\circ}$, in kcal versus $1 / \mathrm{T}\left({ }^{\circ} \mathrm{K}\right)$ for the reduction $\mathrm{CO}$ and $\mathrm{CO}_{2}$ by boron.

[J. P. Coughlin, Contributions to the Data on Theoretical Metallurgy, Nat. Bur. Standards Bulletin $54 \overline{2}(\overline{195} 4 \overline{\text {. }}$

W. H. Evans, D. D. Wagmun, and E. J. Prosen, Thermodynamic Properties of Some Boron Compounds, Nat. Bur. Standards Report No. 4943 (August 31 , $\overline{1956) .]}$ 


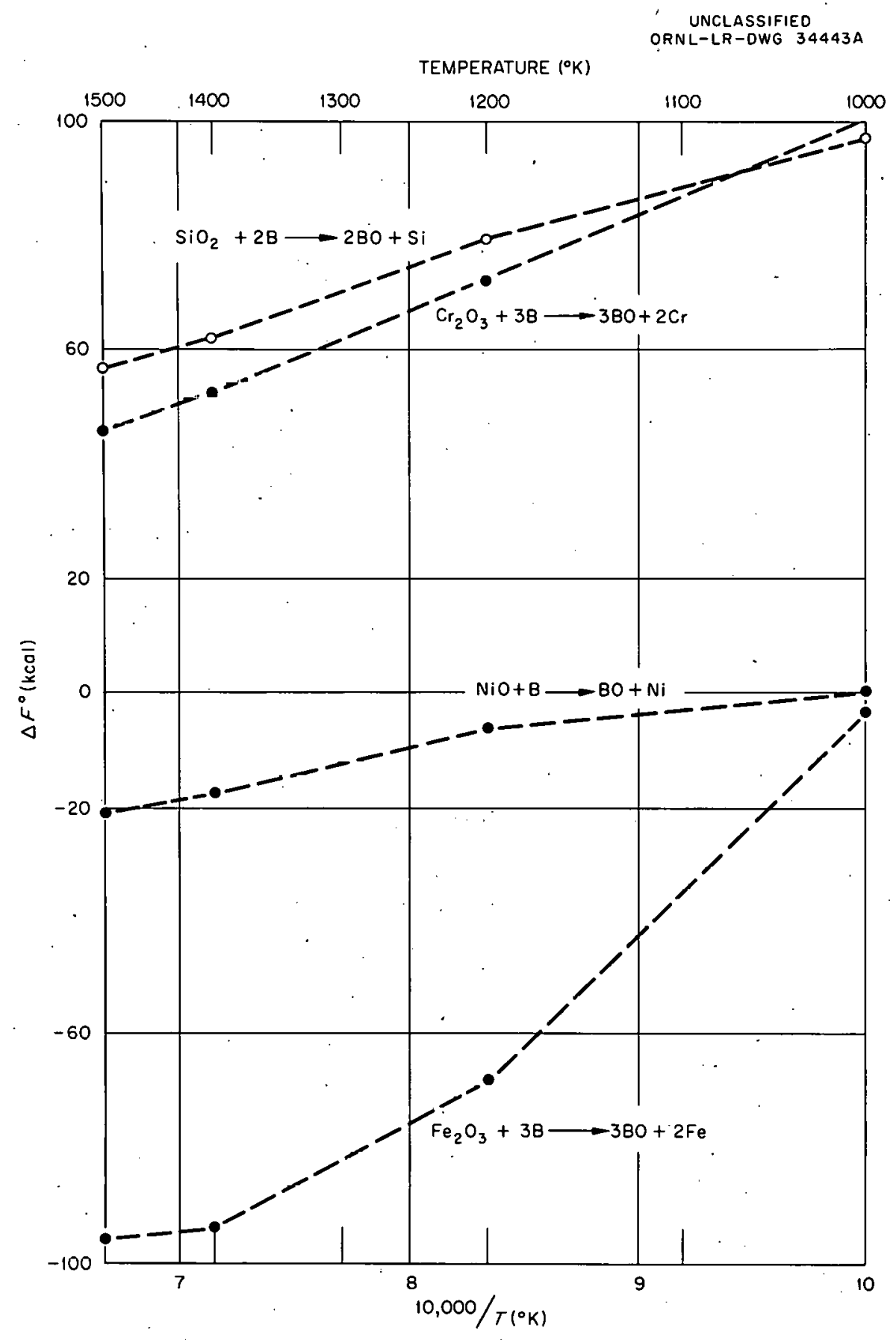

Figure $\dot{3}(\mathrm{a})$. The standard free energy of formation, $\Delta F^{\circ}$, versus $I / T$ for the oxidation of boron. to BO by various oxides.

[J. P. Coughlin, Contributions to the Data on Theoretical Metallurgy, Nat. Bur. Standards Bulletin $54 \overline{2}(\overline{195} 4 \overline{\text {. }}$

W. H. Evans et al., Thermodynamic Properties of Some Boron Compounds, Nat. Bur. Standards Report No. 4943 (August 31, $\overline{1956)}$.] 


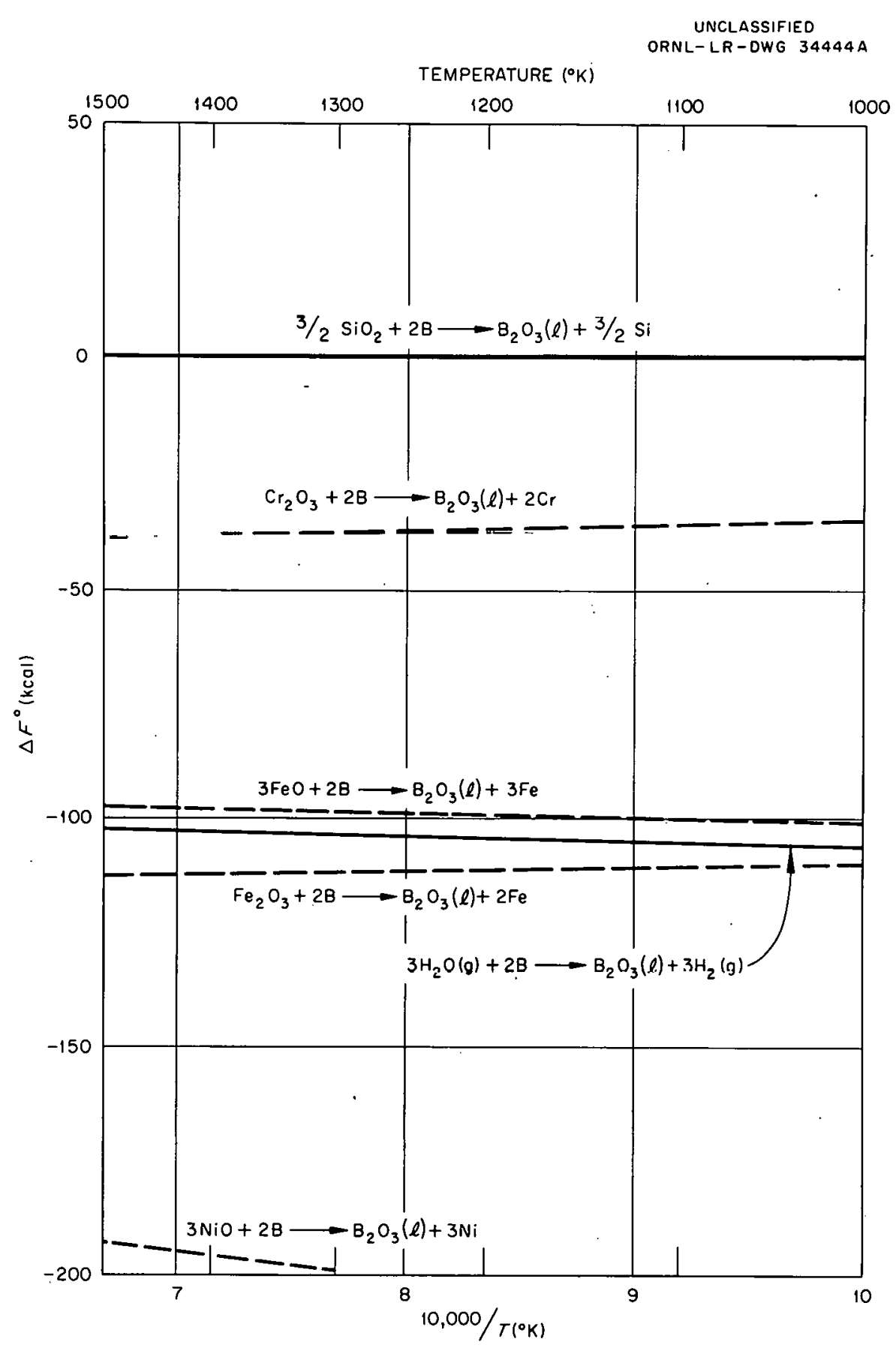

Figure $3(\mathrm{~b})$. The standard free energy of formation, $\Delta F^{\circ}$, versus 1/I f for the oxidation of boron to $\mathrm{B}_{2} \mathrm{O}_{3}$ by various oxides.

[J. P. Coughlin, Contributions to the Data on Theoretical Metallurgy, Nat. Bur. Standards Bulletin $542(\overline{195} 4)$.

W. H. Evans et al., Thermodynamic Properties of Some Boron Compounds, Nat. Bur. Standards Report No. 4943 (August 3i, $\overline{1956)}$.] 
UNCLASSIFIED

ORNL - LR-DWG 51076

TEMPERATURE $\left({ }^{\circ} \mathrm{K}\right)$

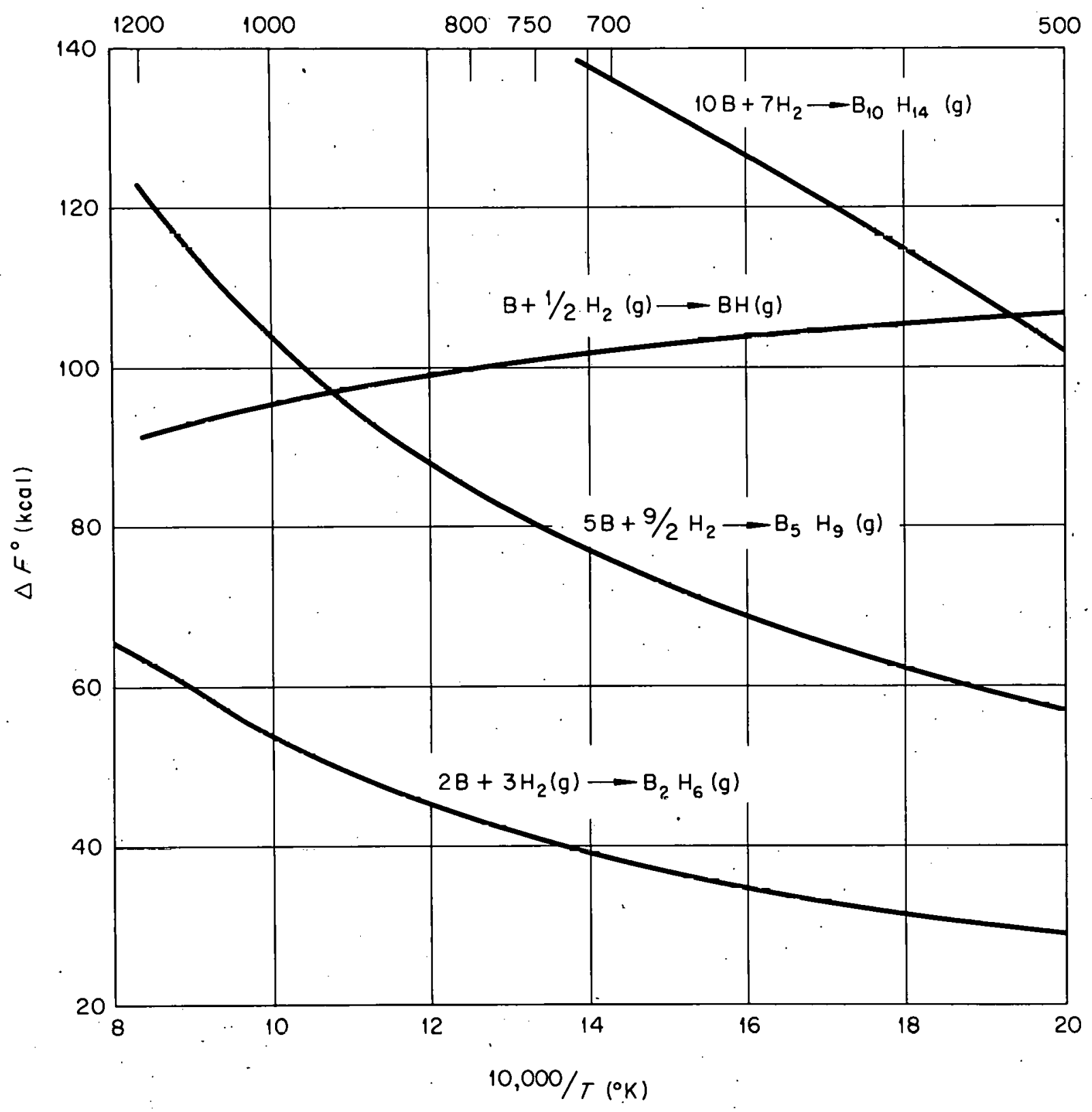

Figure 4. The standard free energy of formation, $\Delta F^{\circ}$, versus $1 / T$ for the formation of various boron-hydrogen. compounds.

[J. P. Coughlin, Contributions to the Data on Theoretical Metallurgy, Nat. Bur. Standards Bulletin $54 \overline{2}(\overline{195} 4)$.

Diborane, Callery Chemical Company Technical Bulletin C-020 (March 15, 1958).] 
that a net collection of boron was experienced at the metal-atmosphere interface of samples deboronized below $1000^{\circ} \mathrm{C}$. The rate of boron lost from the metal surface should increase with temperature proportionally to the $\mathrm{B}_{2} \mathrm{O}_{3}$ vapor pressure until steady-state equilibrium with the boron diffusing to that surface is attained.

According to Margrave et al. (23) the loss of boron from systems containing water vapor may be more complex than simple volatilization as $\mathrm{B}_{2} \mathrm{O}_{3}$. They found that water vapor would react with $\mathrm{B}_{2} \mathrm{O}_{3}(l)$ to form $\mathrm{H}_{3} \mathrm{BO}_{3}$ according to

$\mathrm{B}_{2} \mathrm{O}_{3}(l)+3 \mathrm{H}_{2} \mathrm{O}(\mathrm{g}) \rightarrow 2 \mathrm{H}_{3} \mathrm{BO}_{3}(\mathrm{~g})$

and

$\log \mathrm{k}=\log \frac{\mathrm{p}^{2}}{\mathrm{p}_{\mathrm{H}_{3} \mathrm{BO}} \mathrm{O}}=-3.903$ at $900^{\circ} \mathrm{K}$ and -2.538 at $1273^{\circ} \mathrm{K}$.

Their experimental conditions were not completely described, although they report that even at $500^{\circ} \mathrm{C}$ the vaporization of $\mathrm{B}_{2} \mathrm{O}_{3}$ is perceptible, if water vapor is present.

Another boron oxide is of interest to this study. Kanda (24) reported the reduction of $\mathrm{B}_{2} \mathrm{O}_{3}$ by boron to the lower oxide, boron monoxide. When $\mathrm{B}_{-} \mathrm{B}_{2} \mathrm{O}_{3}$ mixtures were heated in a vacuum furnace at pressures lower than $10^{-4}$ millimeters of mercury and temperatures greater than $1050^{\circ} \mathrm{C}$, an amorphous, amber, glassy deposit, identified as a boron monoxide polymer, collected in the cooler portions of the furnace. 
Kanda also observed that the substance disproportionated into boron and boron sesquioxide when heated above $450^{\circ} \mathrm{C}$.

An alternate mode of boron escape from boron-bearing alloys during heat treatment in hydrogen is the formation and subsequent volatilization of a boron-hydrogen species such as diborane, $\mathrm{B}_{2} \mathrm{H}_{6}$.

Although the formation of hydrogen-boron compounds is thermodynamically unfavorable at elevated temperatures, as shown in Figure 4, page 14, the synthesis of diborane has been observed $(17,25)$. Newkirk (26) reported that diborane f'orms in small quantities when dry hydrogen is passed over elemental boron at $840^{\circ} \mathrm{C}$. Belle and Benington (27) reported that 23 cubic centimeters (STP) of gaseous reaction products, predominantly diborane, were trapped in a liquid nitrogen cold trap when 30 grams of calcium boride were heated at $909^{\circ} \mathrm{C}$ for $45.5^{\circ}$ hours in a stream of hydrogen (35-40 cubic centimeters per minute, STP) at 20 millimeters of mercury. The 0.25 milligram of diborane per hour corresponds to a considerably higher yield tharı would be expected by equilibrium calculations based on the available thermodynamic data. Similar reaction products were noted when elemental boron, ferro boron, and nickel boride were substituted for the calcium boride.

It has been postulated that the mode of formation of diborane is the formation of an intermediate boron-hydrogen species at high temperatures which decomposes at lower temperatures yielding diborane $(27,28)$. For example, Kanda (24) reported that boron monoxide polymer reacts with water to form boron sesquioxide and some boron 
hydrides. Such an explanation would obviously involve a different thermodynamic treatment than an elemental synthesis producing diborane.

\section{KINETICS OF THE BORON LOSS}

Regardless of the specific nature of the solid-gas reaction responsible for boron transport from boron-bearing systems heat treated in hydrogen, three alternative rate-determining steps may be considered: diffusion of boron to the gas-metal surface, rate of boron atmosphere interaction, and/or the evaporation rate of a boron-containing reaction product from the sample.

If the loss of boron from an iron-boron alloy at temperatures in excess of $1000^{\circ} \mathrm{C}$ is controlled by the rate of boron diffusion to the gas-metal interface rather than the rate of compound volatilization, then, in geometrically simple samples, the loss rate can be quantitatively predicted by the laws of diffusion. Consider an alloy agglomerate of metal borides dispersed homogeneously in a matrix of low boron solid solubility. If the alloy is heat treated in such a way as to deboronize it, a two-phase central core surrounded by a single-phase layer will result. An analogous situation of diffusion into a singlephase alloy to produce movement of the boundary with an abutting twophase alloy has been described by Wagner (29). Figure 5(a) illustrates the situation as presented by Wagner, and Figure 5(b) illustrates the comparable situation of immediate interest. Wagner has shown that

$$
\zeta=\gamma 2 \sqrt{D_{I I} t}
$$



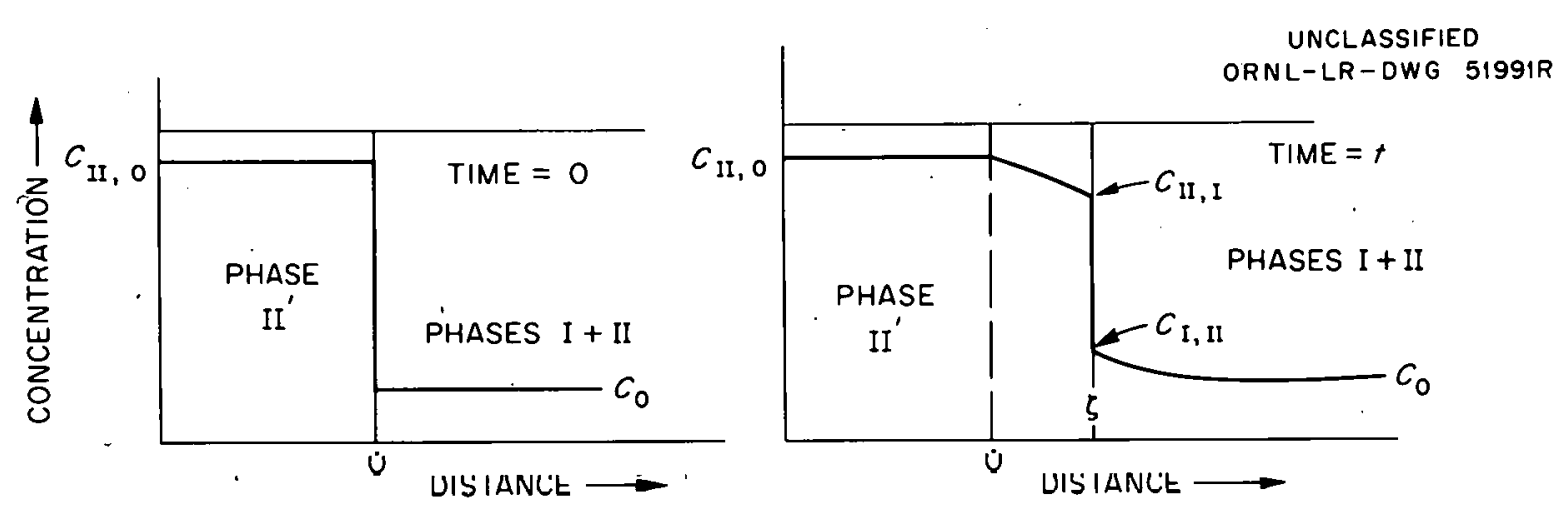

(a)
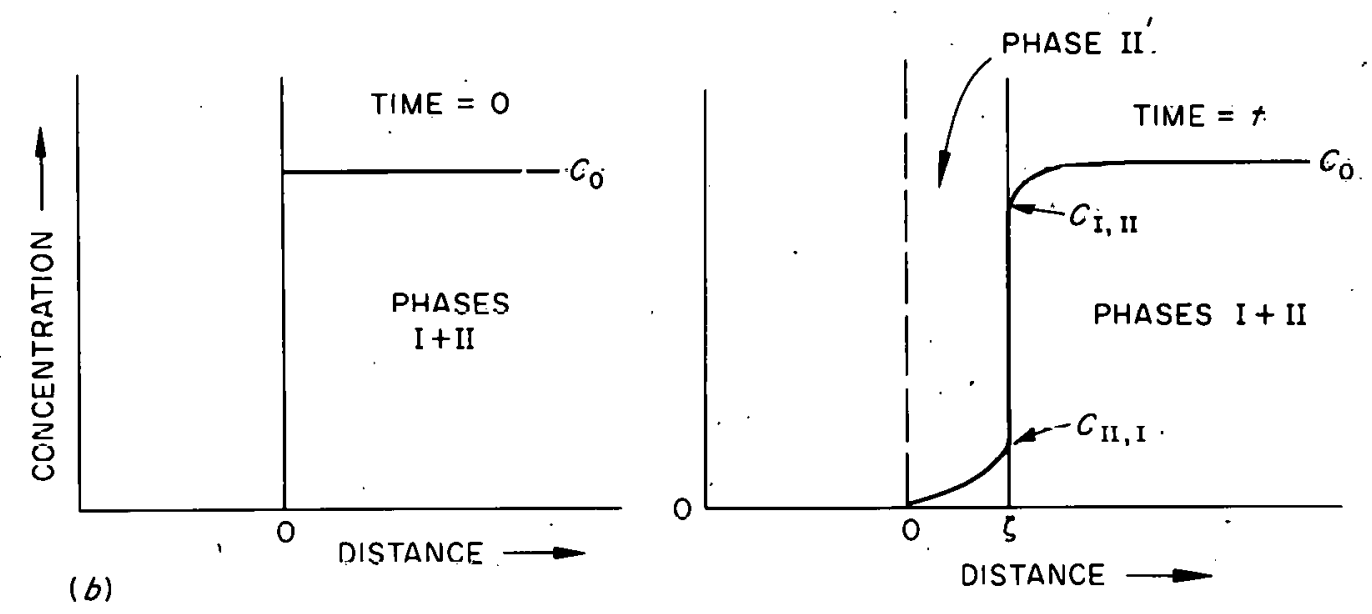

Figure 5. Model of deboronization from an infinite sheet of two-phase boron-stainless steel alloy assuming boron loss rate is controlled by solid-state diffusion. (a) Wagner model, * (b) is an obvious modification to describe deboronization.

(*W. Jost, Diffusion in Solids, Liquids, and Gases, pp. 72-73, Academic Press, New York, 1952.) 
where

$$
\begin{aligned}
& \zeta=\text { distance moved by the boundary of Phase II and the agglomerate } \\
& \quad \text { of Phase } I \text { and II, } \\
& D_{I I}=\text { diffusion coefficient of species }(B) \text { from dissolving Phase } I \text {, } \\
& t=\text { time, and } \\
& \quad \gamma=\text { dimensionless constant defined by } \\
& \frac{C_{I I, O^{-C}} C_{I I, I}}{C_{I I, I}}=\sqrt{\pi} \gamma \exp \left(\gamma^{2}\right)[I+\operatorname{erf} \gamma],
\end{aligned}
$$

the concentrations, $\mathrm{C}$, being defined in Figure 5(a), page 18.

As demonstrated in Appendix I, the fractional depletion of boron from a specimen in such a situation is linearly proportional to the square root of time or

$\Delta B=k_{1} t^{1 / 2}$

where $\mathrm{k}_{1}$ is a proportionality constant. The corresponding calculated $\zeta$, as found by Newton's method (30), and the fractional boron depletion as a function of time are presented in Table $I$.

Alternately, the rate-controlling process could be either the rate of reaction of the boron with the surrounding atmosphere at the gas-metal interface or by the specific volatilization rate of boronbearing reaction products. Considering the dynamic nature of the gas system and the constant surface area of the model under consideration, the rate of boron lost, $\Delta B / \Delta t$ or $\Delta B$, would be independent of time and, correspondingly, the total boron loss would be a linear function of time or 
TABLE I

CALCULATED VALUES OF $\zeta^{*}$ AND THE CORRESPONDING FRACTIONAL BORON DEPLETION FOR BORON-STAINLESS STEEL ALLOY

HEAT TREATED AT $1135^{\circ} \mathrm{C}$

\begin{tabular}{ccc}
\hline $\begin{array}{c}\text { Heat-Treatment } \\
\text { Time (hr) }\end{array}$ & $\zeta$ Calculated \\
$(\mathrm{cm})$ & $f_{\mathrm{d}}^{* *}$ \\
\hline 1 & 0.0121 & 0.149 \\
2 & 0.0171 & 0.211 \\
4 & 0.0242 & 0.304 \\
8 & 0.0342 & 0.423 \\
16 & 0.0485 & 0.610 \\
\hline
\end{tabular}

${ }^{*} \zeta=$ depth of single-phase deboronized zone.

** Based on an 0.078 inch thick specimen originally containing 0.13 weight per cerit boron and neglecting end effects. 
$\Delta \mathrm{B}=\mathrm{k}_{2} \mathrm{t}$,

where $\mathrm{k}_{2}$ is a proportionality constant.

The mechanism of loss of boron from a boron-bearing alloy powder compact is considerably more complex. Consideration must be given to: rates of boron diffusion to the gas-metal interface, the boron-atmosphere reaction rate, the rate of volatilization of the boron-bearing reaction product, and the decrease of the compact's surface area with sintering. Regardless of the predominant mechanism of boron escape from the sample, the changing surface area is a significant factor.

Additionally, if the loss rate is solid-state diffusion controlled, it would be independent of environmental changes which alter the boron-bearing species leaving the sample surface. In such a case, the only effect of heat-treating environment, if any, would be restricted to its influence on the sintering rate of the compact and the associated decrease in total exposed surface area. 
CHAPTER IV

EXPERIMENTAL PROCEDURE

I. QUALITATIVE STUDY OF ENVIRONMENTAL EFFECTS.

The mode of boron loss was examined by sintering, under selected environmental conditions, compacts of high-purity boron mechanically dispersed in a matrix of the constituents commonly found in austenitic stainless steel powder. Boron losses were determined by means of analytical chemistry.

\section{Compact Preparation."}

Powder mixtures were prepared consisting of 0.050 gram of -325 . mesh elemental boron containing 97.04 weight per cent boron, 0.10 weight per cent carbon, 0.16 weight per cent iron, balance adsorbed gases and water, and one gram of either $\mathrm{SiO}_{2}, \mathrm{Si}, \mathrm{NiO}, \mathrm{Ni}, \mathrm{Cr}_{2} \mathrm{O}_{3}, \mathrm{Cr}$, $\mathrm{Fe}_{2} \mathrm{O}_{3}$, or $\mathrm{Fe}$. The matrix metal and metal oxide powders were all of reagent quality and, consequently, specific chemical analyses were not made. The boron and appropriate matrix material were blended manually by tumbling. An addition of 0.1 cubic centimeter of 5 weight per cent camphor in ethyl alcohol was added to and distributed in the metal oxide-boron mixtures to facilitate pressing. The addition was unnecessary in the metal-boron mixtures.

The powder mixes were consolidated in a double-acting, one-half inch diameter, right cylindrical die. A tive-eighths inch diameter die 
was used to consolidate the metal oxide-boron and silicon-boron compacts to ensure a reproducibly integral compact. Prior to each compact fabrication, the die plungers and cavity were carefully cleaned with acetone and lubricated with a saturated solution of stearic acid in acetone. The bottom plunger was then inserted in the cavity, the charge poured into the cavity with care to ensure a maximum amount of powder transfer, and a shorter top plunger inserted. The compacts were pressed at 33 tons per square inch pressure. The top plunger was then removed and the compact ejected by forcing the bottom plunger upward. Each compact was then placed in a dried, one-inch diameter, circular alumina dish. The compact-dish assembly was stored in a vacuum desiccator for a minimum of twenty hours prior to sample heat treatment to allow the volatile organic constituents to evaporate.

\section{Heat Treatment}

Compacts of each material combination were heat treated for one and one-fourth hours at $1135^{\circ} \mathrm{C}$ in five environments: vacuum, highpurity argon, wet helium $\left(1.4 \times 10^{5}\right.$ parts per million $\left.\mathrm{H}_{2} \mathrm{O}\right)$, hydrogen (460 parts per million $\mathrm{H}_{2} \mathrm{O}$ ), and hydrogen (less than 7 parts per million $\mathrm{H}_{2} \mathrm{O}$ ). Both the vacuum and atmosphere furnaces were electrically heated, horizontal tube furnaces. The temperature was controlled by a Wheelco proportioning controller activated by platinum-platinum-10 per cent rhodium thermocouple. The maximum temperature fluctuation at $1135^{\circ} \mathrm{C}$ was $\pm 2^{\circ} \mathrm{C}$ in the useful hot zone, and the measured temperature gradient in that zone was $\pm 2^{\circ} \mathrm{C}$. Reproducibility of temperature during heat treatments is estimated at $\pm 5^{\circ}$.C. 
Vacuum System

The vacuum system, illustrated in Figure 6, consisted of a fused quartz, one and one-half inch inside diameter muffle (A) incorporating a specimen transfer arrangement (B) in the end cap (C). A five-mildiameter platinum wire was attached to an arbor ( $\mathrm{B}^{\prime}$ ) which could be manually rotated through a glass vacuum seal (D) while maintaining a vacuum in the furnacc muffle. The other wire end was attached to a boat located in the far end of the muffle. The operating sequence included (1) load furnace cold, (2) evacuate, (3) heat to $1135^{\circ} \mathrm{C}$, (4) draw samples into hot zone and heat treat, (5) withdraw samples into cold zone and allow samples and furnace to cool, and (6) unload. Associated equipment included an MCF 300 diffusion pump backed by a mechanical roughing pump. A cold trap was not incorporated in . the system because of the tremendous amount of outgassing of the powder metallurgical compacts during the relatively short heat-treating times. Both thermocouple and an ion gauge $(E)$, when appropriate, were used to ascertain the vacuum. The furnace temperature was continuously recorded.

\section{Atmosphere System}

The atmosphere furnace system, illustrated in F'igure 7, consisted of an Inconel muffle (F) with an integral water-cooled extension (G) for sample loading prior to hot-zone insertion and for postheat-treat cooling. Samples were loaded into the cold zone while flushing the muffle with.helium or argon, the muffle end door (H) closed, the appropriate gas passed through the furnace, and the boat containing the 


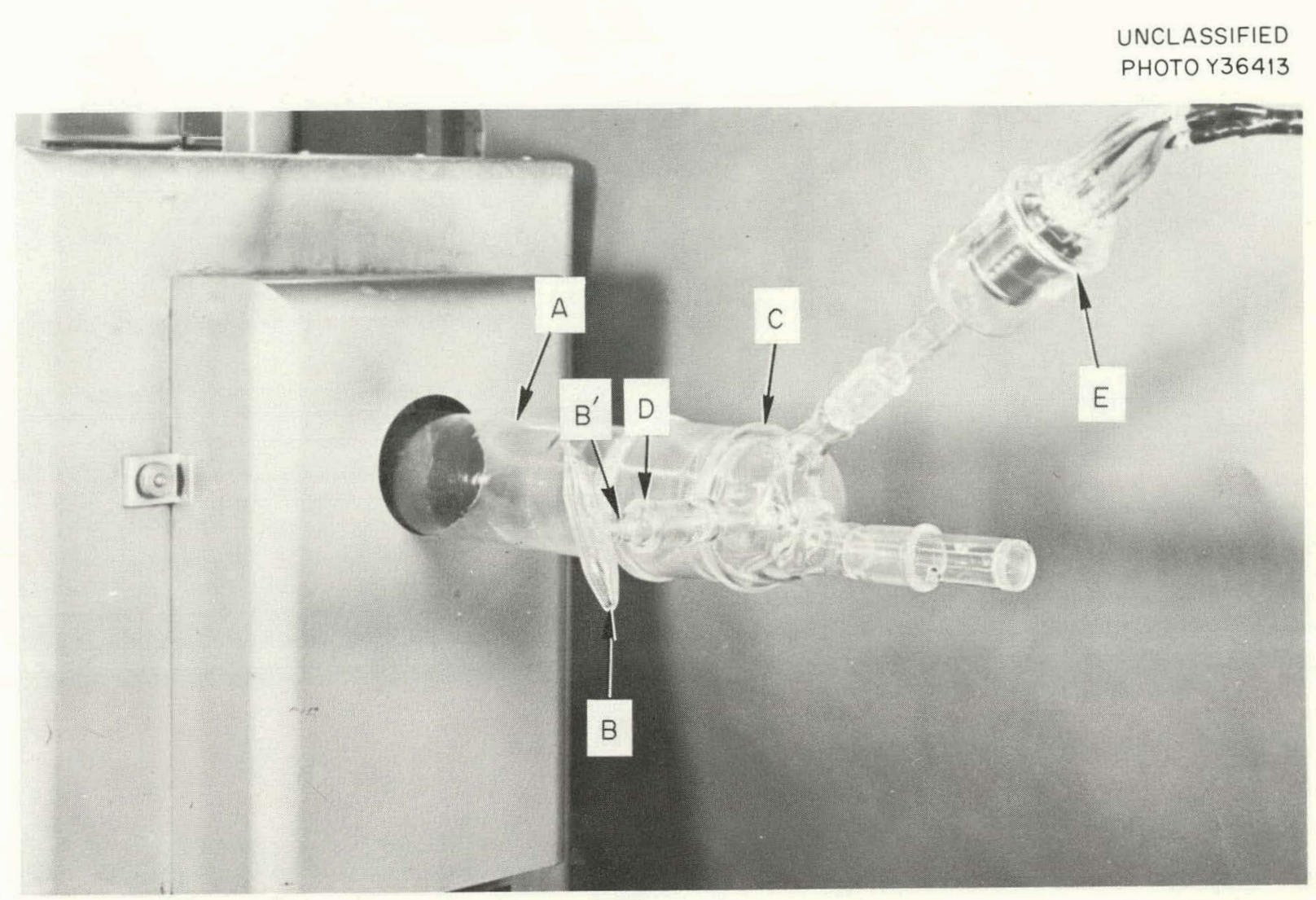

Figure 6. Loading end of the vacuum tube furnace. 


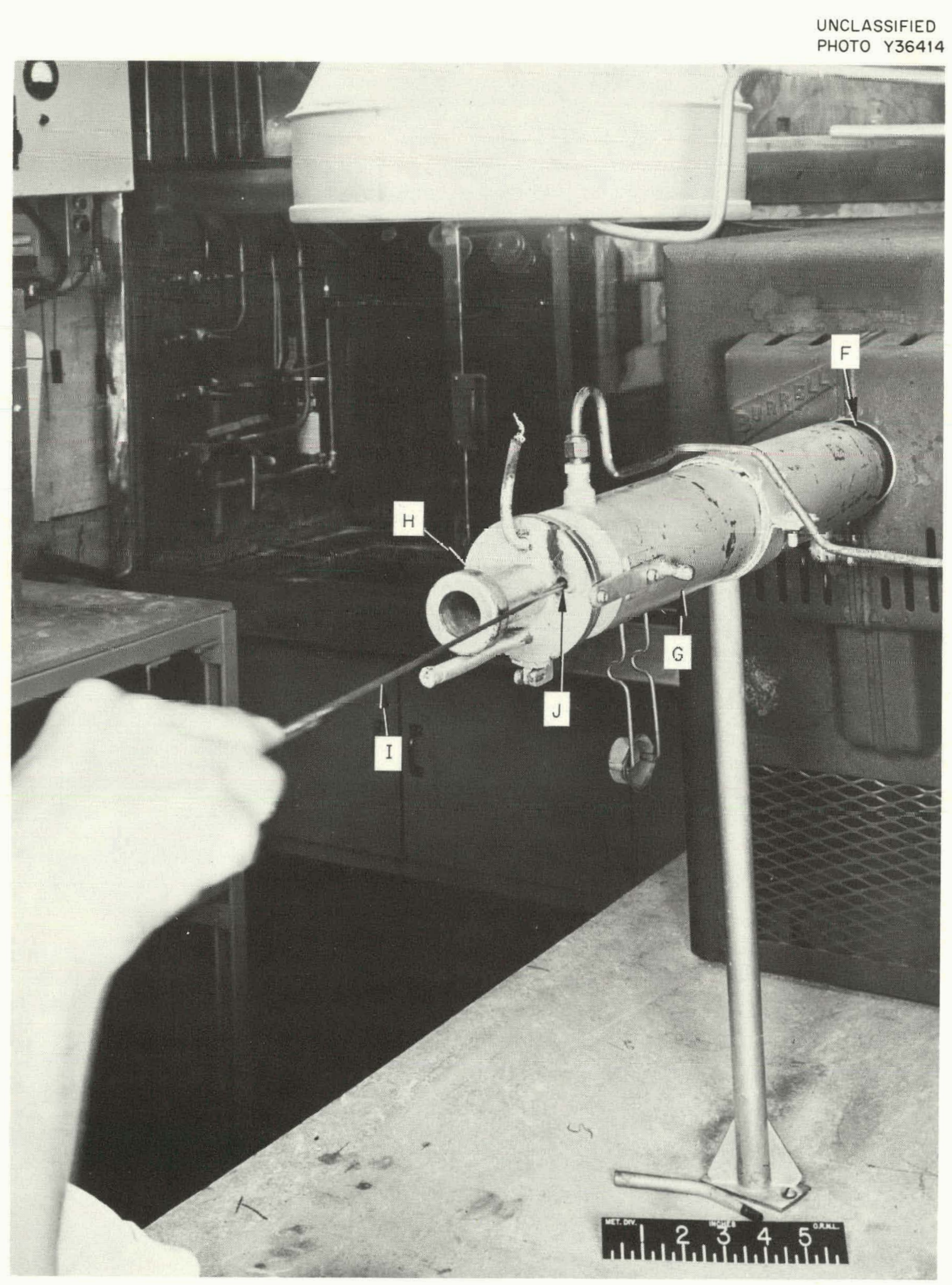

Figure 7. Ioading end of the atmosphere furnace. 
samples pushed into the hot zone by a rod (I) inserted into the muffle through a small hole $(J)$ in the door.

The high-purity argon used was obtained directly from a tank. Its composition, as determined by a mass spectrograph, is given in Table II. Tank hydrogen and helium were purified by passing through a Deoxo unit followed by drying in an "Electrodrier" containing activated alumina. The exit hydrogen contained less than 7 parts per million $\mathrm{H}_{2} \mathrm{O}$ as measured by a Beckman hygrometer.

The water vapor contained in the gases was controlled by bubbling the gas through either sulfuric acid of the appropriate concentration or through water. The conditioning assembly, illustrated in Figure 8, consisted of three 500-milliliter gas-washing bottles (K) in series, each filled with two inches of the appropriate desiccant. The apparatus was contained in an isothermal water bath $(L)$. The gas, after bubbling through the equivalent of six inches of liquid, was trapped. (M) to remove any acid or moisture droplets, and passed through a calibrated "U" tube manometer (N) before entrance into the furnace (O). Unless otherwise noted, gas flow rate was held at $20 \pm 5$ cubic feet per hour at one atmosphere and $20^{\circ} \mathrm{C}$.

To evaluate the effect of essentially pure hydrogen, the hydrogen from the alumina driers was passed through a liquid nitrogen cold trap which lowered the residual water content to less than one part per million. Effects of water vapor were considered in relation to this "dry" hydrogen. 
TABLE II

TYPICAL MASS SPECTROGRAPHIC ANALYSIS OF HIGH-PURITY ARGON

\begin{tabular}{lc}
\hline \hline Species & Concentration \\
\hline $\mathrm{H}_{2} \mathrm{O}$ & $<1 \mathrm{ppm}$ \\
$\mathrm{CH}_{4}$ & $16 \mathrm{ppm}$ \\
$\mathrm{N}_{2}+$ CO & $30 \mathrm{ppm}$ \\
Other hydrocarbons & $0.3 \mathrm{ppm}$ \\
$\mathrm{A}$ & $99.995 \%$ \\
\hline
\end{tabular}


UNCLASSIFIED

PHOTO Y 36412

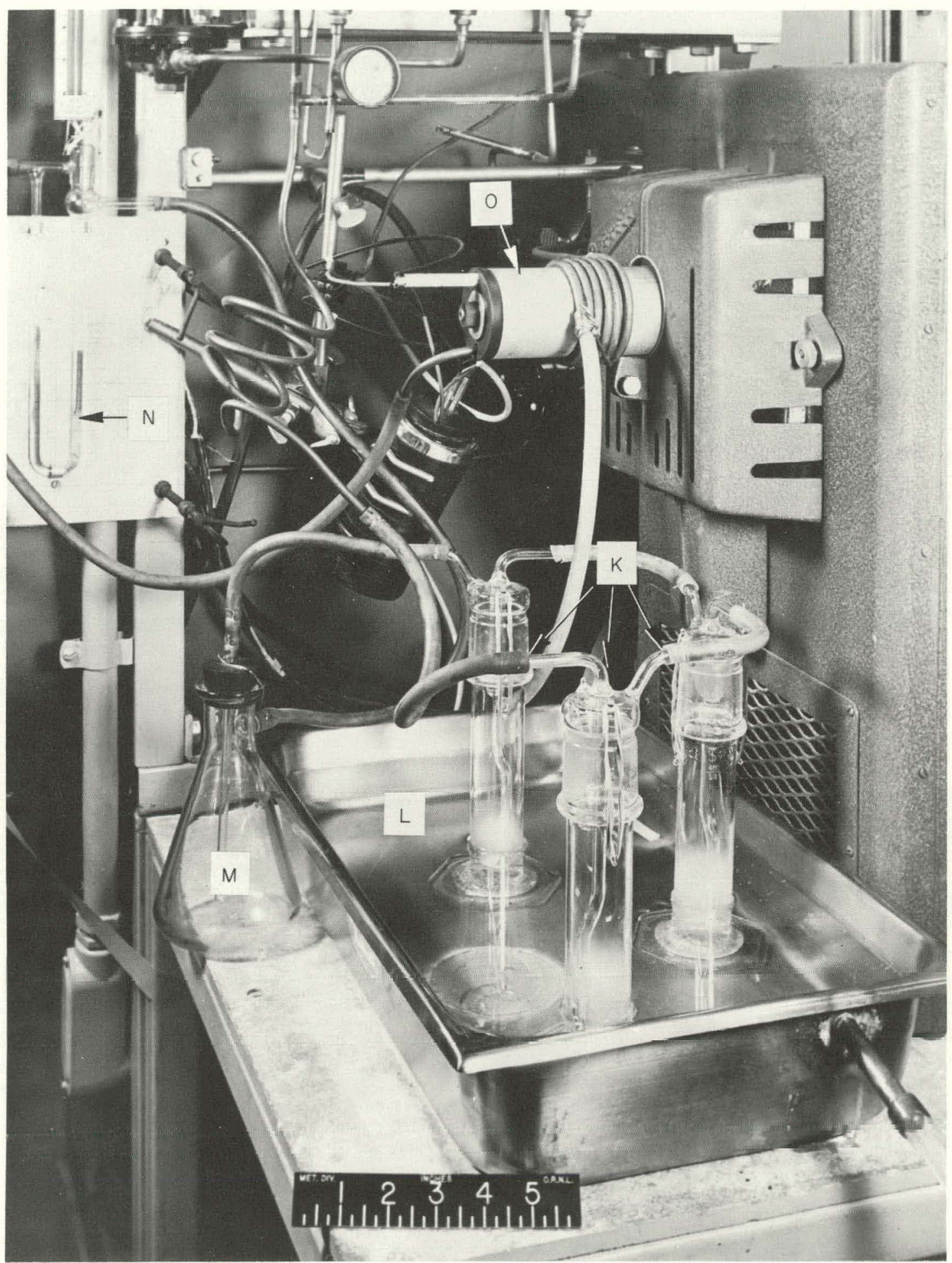

Figure 8. Gas conditioning apparatus. 
Postheat Treatment

The specimens, after heat treatment, were withdrawn into the cooler portion of the furnace and allowed to reach room temperature before atmospheric exposure. They were visually examined, weighed, and chemically analyzed to ascertain the boron content. Accuracy of boron analysis is estimated at \pm 5 per cent. The per cent boron loss from each compact was calculated according to

per cent boron lost $=\frac{\Delta B}{B_{0}} \times 100$

where $\triangle B$ is the original nominal boron content $\left(B_{0}\right), 48.52$ milligrams, less the boron found after heat treatment (in milligrams).

\section{KINETICS OF BORON LOSS FROM BORON-STAINLESS STEEL ALLOYS}

The boron-loss kinetics from a metallurgically consolidated, five-gram compact of 0.25 weight per cent boron-stainless steel alloy powder were examined during heat treatment in hydrogen. These conditions approximated those under which boron losses had been observed during SM-1 fuel fabrication.

To investigate the effect of solid-state diffusion alone, it became necessary to eliminate the effects of those variables inherently associated with powder compacts such as undefined surface area and geometry and particle sintering. Therefore, the boron-loss characteristics of 0.14 weight per cent boron-stainless steel wrought alloy sheet were determined. 


\section{Master Alloy Preparation}

Compacts of 9.00 grams of high-purity enriched boron (92.74 atomic per cent boron-10) and 48.75 grams of nickel powder were prepared by cold pressing the blended powders at 33 tons per square inch in an 0.8 inch diameter die and sintering for one-half hour at $845^{\circ} \mathrm{C}$ in dry hydrogen. The compacts were then vacuum arc melted, crushed, and the resultant nickel boride used as a boron-bearing addition to a twentyfive pound type 304L stainless steel heat. The heat was converted into a powder by atomization. The particle size analysis and composition of the resultant boron-bearing stainless steel alloy powder, which will be referred to as master alloy, are given in Table III. The series of analytical boron determinations, listed in Table IV, were used to compute an average boron content of the master alloy as 0.25 weight per cent.

\section{Master Alloy Compact Preparation}

Compacts were prepared by pressing 5.00 grams of master alloy at 33 tons per square inch in a one-half inch diameter, double-acting, right cylindrical die. Weights of the "green" compacts were not recorded since adsorption of varying amounts of die lubricant (saturated. stearic acid-acetone solution) made such measurements meaningless. However, reproducibility of the metal charge is estimated at \pm 0.020 grälu. 
TABLE III

\begin{tabular}{cc}
$\begin{array}{c}\text { COMPOSITION AND SCREEN ANALYSIS OF THE } \\
\text { TYPE 304 MASTER ALIOY }\end{array}$ & Weight Per Cent \\
\hline Constituent & 18.98 \\
$\mathrm{Cr}$ & 9.73 \\
$\mathrm{Ni}$ & 0.034 \\
$\mathrm{Mn}$ & 1.52 \\
$\mathrm{Si}$ & 2.22 \\
$\mathrm{Fe}$ & 66.52 \\
$\mathrm{O}$ & 0.22 \\
\hline
\end{tabular}

\begin{tabular}{lc}
$\begin{array}{c}\text { Size Fraction } \\
(\text { mesh })\end{array}$ & 0.7 \\
+100 & 6.8 \\
$-100+120$ & 12.9 \\
$-120+140$ & 10.8 \\
$-140+170$ & 10.0 \\
$-170+200$ & 9.9 \\
$-200+230$ & 12.4 \\
$-230+270$ & 9.9 \\
$-270+325$ & 26.6 \\
-325 & 100 \\
\hline Total & \\
\hline \hline
\end{tabular}


TABLE IV

BORON CONTENT DETERMINATIONS OF MASTER ALLOY

\begin{tabular}{|c|c|}
\hline $\begin{array}{c}\text { Analysis } \\
\text { Designation }\end{array}$ & $\begin{array}{c}\text { Weight Per Cent } \\
\text { Boron }\end{array}$ \\
\hline 1 & 0.261. \\
\hline 2 & 0.251 \\
\hline 3 & 0.261 \\
\hline 4 & 0.280 \\
\hline 5 & 0.261 \\
\hline 6 & 0.251 \\
\hline 7 & 0.261 \\
\hline 8 & 0.250 \\
\hline 9 & 0.250 \\
\hline 10 & 0.254 \\
\hline 11 & 0.252 \\
\hline 12 & 0.238 \\
\hline 13 & 0.244 \\
\hline 14 & 0.250 \\
\hline 15 & 0.247 \\
\hline
\end{tabular}


Wrought Alloy Preparation

A charge of 127.2 grams of a special heat of 2.17 weight per cent boron-stainless steel alloy and 17.16 grams of type 30,4 scrap was vacuum-induction melted and chill cast into an 8 inch by 3 inch by 0.750 inch graphite mold. The billet top and bottom were cropped and 0.2 inch of material removed from the remaining sides. It was then homogenized by vacuum annealing at $900^{\circ} \mathrm{C}$ for seventy hours followed by two hours at $1000^{\circ} \mathrm{C}$. The billet was rolled at $900^{\circ} \mathrm{C}$ to 0.060 inch thick, a total reduction of $6: 1$. The sheet was then sheared into onehalf by three-fourths inch coupons. The base metal composition of the alloy and the multiple boron determinations performed to demonstrate boron homogeneity of the alloy are compiled in Table V.

Heat Treatment and Evaluation

Handling procedures and equipment were identical to those employed in the Phase I section (Chapter IV, page 22). The effects of heat-treatment time ( 0 to 16 hours) and the moisture content ( 1,100 , and 460 parts per million) and flow rate (20 and 40 cubic feet per hour) of the heat-treating atmosphere, hydrogen, were determined. Boron losses were determined analytically.

Representative deboronized samples of the wrought alloy were examined metallographically. 
TABLE V

COMPOSITION OF THE WROUGHT BORON-BEARING
STAINLESS STEEL ALLOY

\begin{tabular}{|c|c|c|}
\hline Constituent & Sample Number & Weight Per Cent \\
\hline $\mathrm{Cr}$ & & 18 \\
\hline $\mathrm{Ni}$ & & 10 \\
\hline $\mathrm{Mn}$ & . & 1.5 \\
\hline $\mathrm{Si}$ & & 0.52 \\
\hline Fe & & Balanee \\
\hline \multirow[t]{5}{*}{ B } & ES-10 & 0.129 \\
\hline & $E S-29$ & 0.128 \\
\hline & ES -64 & 0.128 \\
\hline & $E S-131$ & 0.136 \\
\hline & FS -141 & 0.121 \\
\hline
\end{tabular}


CHAPTER V

RESULTS AND DISCUSSION

I. QUALITATIVE DETERMINATION OF THE MECHANISM OF BORON LOSS

Vacuum Environment Heat Treatment

The boron losses incurred by compacts containing 0.050 gram high-purity boron and one gram of a selected metal or a metal oxide and heat treated for one and one-fourth hours at $1135^{\circ} \mathrm{C}$ in vacuum are presented in Table VI. Two or three compacts of each matrix type were simultaneously heat treated and the average and individual losses are included in the table. Significantly larger losses were experienced by samples containing a metal oxide matrix than by those containing a pure metal matrix.

The small losses rècorded for samples of a pure metal matrix are attributed to (1) mechànical factors including weighing error, handling loss, and temporal variations of the quantity of adsorbed water on the finely divided boron and (2) chemical factors including partial boron oxidation by the residual oxygen content of the "pure" metal powders. The oxygen content of the metal powders averaged 0.25 per cent or $1.6 \times 10^{-4}$ mole per compact which can contribute a maximum loss of 2.5 per cent of the $4.5 \times 10^{-3}$ mole of boron originally present, if conversion to and volatilization of boron sesquioxide is postulated as the loss mechanism. 
TABLE VI

BORON LOSS FROM COMPACTS OF 5. WEIGHT PER CENT BORON VACUUM HEAT TREATED* AT $1135^{\circ} \mathrm{C}$ FOR ONE AND ONE-FOURTH HOURS

\begin{tabular}{|c|c|c|c|c|c|}
\hline \multirow[b]{2}{*}{ Matrix } & \multicolumn{4}{|c|}{ Boron Loss, \% } & \multirow[b]{2}{*}{ Postsinter Appearance } \\
\hline & 1 & 2 & 3 & $\overline{A v}$ & \\
\hline Si. & 2.3 & 1.7 & 3.8 & 2.6 & \\
\hline $\mathrm{SiO}_{2}$ & 13.6 & 11.0 & & 12.3 & Glassy appearance \\
\hline $\mathrm{Ni}$ & 1.4 & 2.1 & 4.1 & 2.6 & Nickel-boron alloy formed \\
\hline $\mathrm{NiO}$ & 33.6 & 29.4 & & 31.5 & $\begin{array}{l}\text { Oxide reduced, nickel-boron } \\
\text { alloy formed }\end{array}$ \\
\hline $\mathrm{Cr}$ & 2.3 & 1.0 & & 1.7 & Porous metallic disk \\
\hline $\mathrm{Cr}_{2} \mathrm{O}_{3}$ & 18.5 & 17.7 & 25.0 & 20.4 & Dense black compact \\
\hline $\mathrm{Fe}$ & 4.4 & 5.4 & 5.4 & 5.1 & Porous metallic disk \\
\hline $\mathrm{Fe}_{2} \mathrm{O}_{3}$ & & & & & $\begin{array}{l}\text { Components reacted and } \\
\text { splattered }\end{array}$ \\
\hline
\end{tabular}

*Less than one micron 
Mechanical losses were evaluated by boron analyses of several as-pressed compacts. Deficiencies as great as six per cent of the intended boron content were recorded although the deficiencies observed in sample groups that were prepared at a given time were relatively consistent. Such variations suggest temporal oscillations of a parameter; for example, the amount of water adsorbed by the elemental powder. Thus, the small but constant boron losses experienced by each pure metal matrix sample of a given series are inconsequential considering the experimental technique. However, they demonstrate the stability of boron in a relatively oxygen-free system.

A source of oxygen and the subsequent oxidation of boron is therefore necessary to secure appreciable boron losses. The oxidation of boron to $\mathrm{B}_{2} \mathrm{O}_{3}$ by any of the oxide matrices investigated is accompanied by a negative free-energy change, as illustrated in Figure 3b, page 13. This was confirmed by visual examination of heat treated $\mathrm{Fe}_{2} \mathrm{O}_{3}-\mathrm{B}$ and NiO-B samples. The former reacted so violently that the products scattered in the furnace, invalidating a quantitative boron determination. The $\mathrm{NiO}-\mathrm{B}$ reacted to form a small metallic spheroid, apparently molten at one time.

Thus, it may be postulated that boron is lost from the compact in a two-step sequence:

$2 \mathrm{~B}+\frac{3}{\mathrm{y}} \mathrm{M}_{\mathrm{x}} \mathrm{O} \mathrm{y} \rightarrow \mathrm{B}_{2} \mathrm{O}_{3}(l)+\frac{3 \mathrm{x}}{\mathrm{y}} \mathrm{M}$

and

$\mathrm{B}_{2} \mathrm{O}_{3}(l) \rightarrow \mathrm{B}_{2} \mathrm{O}_{3}(\mathrm{~g})$. 
In such a sequence, regardless of the rate-controlling step, boron losses from a given material combination should increase with time. Compacts containing five per cent boron in $\mathrm{Cr}_{2} \mathrm{O}_{3}$ were vacuum sintered at $1135^{\circ} \mathrm{C}$ for twenty-four hours. Losses of 46.5 and 43 per cent were realized. Based on the cited reaction sequence and compositions of the compacts, a loss of one hundred per cent would be expected if sufficient time were allowed, Table VII 'lists the moles of oxygen originally' available in each compact and moles of boron remaining after complete conversion of the available oxygen to $\mathrm{B}_{2} \mathrm{O}_{3}$. In any case, all of the boron can be oxidized to $\mathrm{B}_{2} \mathrm{O}_{3}$.

Figure 9 is a photograph of the central cross section of a. vacuum heat-treated $\mathrm{Cr}_{2} \mathrm{O}_{3}$-B compact. The compact structure suggests that a considerable amount of oxide reduction has occurred, as has sintering and the resultant densification of the compact. Presumably then, as compact sintering proceeds, both the apparent and real surface area of the sample decrease as well as the effective size and number of surface-connected interparticle passages. Since the mean free path of the gaseous species is constant, the increase in effective path length of the surface-connected channels through which the gaseous $\mathrm{B}_{2} \mathrm{O}_{3}$ molecule must diffuse results in a reduction of the loss rate. The observed decrease in the rate of boron loss and the difficulty in approaching the theoretical maximum loss value are, therefore, consistent with the physical nature of the system. 
TABLE VII

STOICHIOMETRIC RELATIONSHIPS FOR THE FORMATION OF $\mathrm{B}_{2} \mathrm{O}_{3}$

\begin{tabular}{|c|c|c|c|c|}
\hline Matrix & $\begin{array}{c}\text { Oxygen } \\
\text { Available } \\
\left(\text { mole } \times 10^{3}\right)\end{array}$ & $\begin{array}{l}\text { Boron Necessary } \\
\text { for Complete } \\
\text { Conversion of } \\
\text { Oxygen to } \mathrm{B}_{2} \mathrm{O}_{3} \\
\left.\text { (mole } \times 10^{3}\right)\end{array}$ & $\begin{array}{c}\text { Oxygen } \\
\text { Excess } \\
\left(\operatorname{mole} \times 10^{3}\right)\end{array}$ & $\begin{array}{l}\text { Maximum } \\
\text { Boron } \\
\text { Conversion } \\
\text { to } \mathrm{B}_{2} \mathrm{O}_{3} \\
(\%)\end{array}$ \\
\hline NiO & 13.3 & 8.9 & 4.3 & 100 \\
\hline $\mathrm{Fe}_{2} \mathrm{O}_{3}$ & 18.8 & 12.5 & 8.0 & 100 \\
\hline $\mathrm{SiO}_{2}$ & 23.4 & 15.6 & 11.1 & 100 \\
\hline $\mathrm{Cr}_{2} \mathrm{O}_{3}$ & 19.7 & 13.1 & 6.6 & 100 \\
\hline
\end{tabular}

* Oxygen in excess necessary to convert the $4.5 \times 10^{-3}$ moles of boron originally present to boron sesquioxide. 


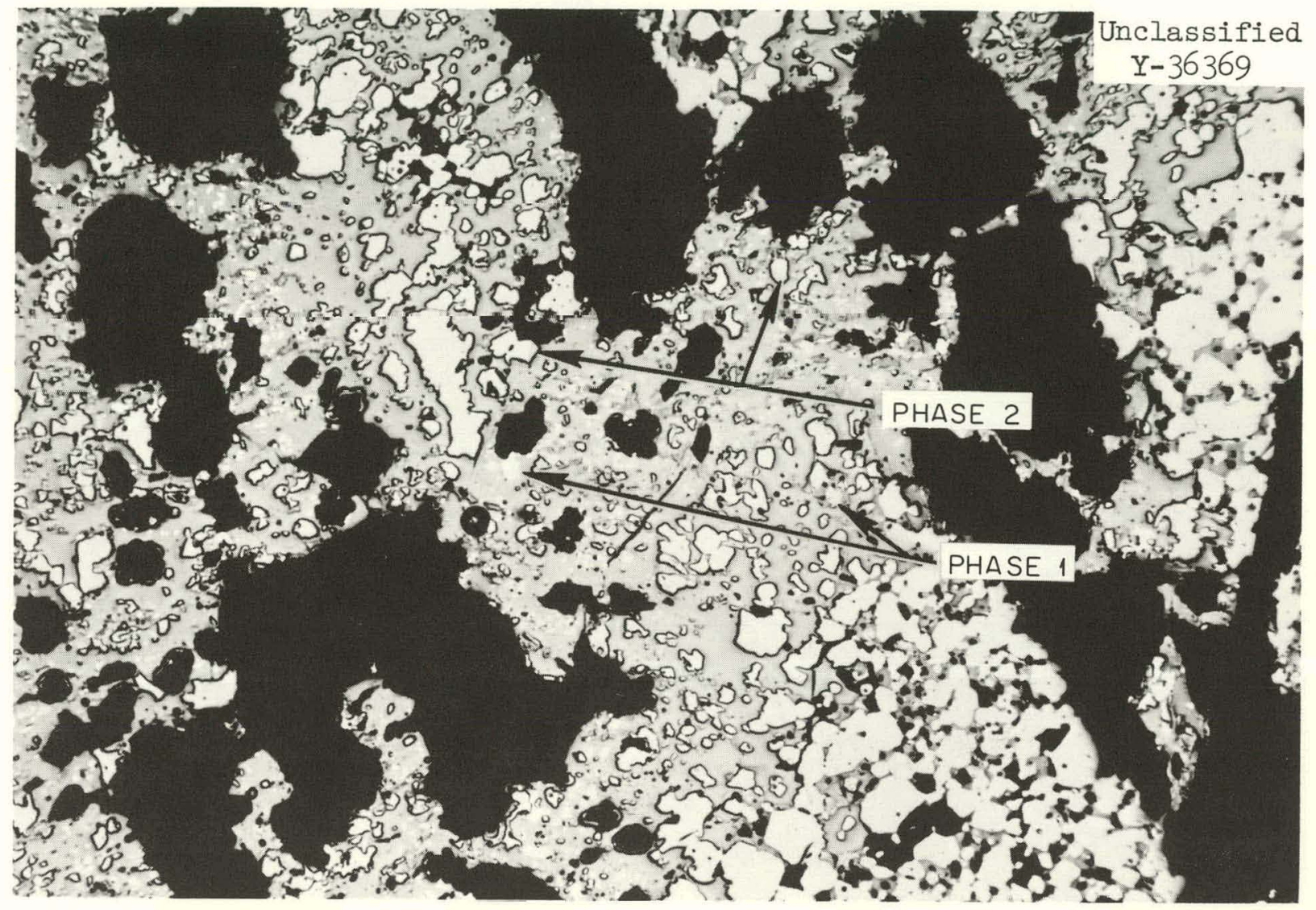

Figure 9. Cross section of a compact originally containing five per cent boron dispersed in $\mathrm{Cr}_{2} \mathrm{O}_{3}$ and vacuum sintered one and one-fourth hours at $1135^{\circ} \mathrm{C}$. Black areas are voids and the solid consists of at least three phases. As polished. 250X. 
In the NiO-B system, assuming the same boron-loss reaction, the lower than anticipated loss can be accounted for by the thermal instability of the nickel oxide. The partial pressure of oxygen in equilibrium with nickel oxide at $1135^{\circ} \mathrm{C}$ is greater than that experimentally realized, and in the dynamic system, the decomposition can continue to completion. Thus, the total amount of boron oxidized is a matter of competing rates of boron oxidation and thermal decomposition of nickcl oxide.

The $\mathrm{SiO}_{2}-\mathrm{B}$ combination presents a very complex situation. The formation of borosilicate compounds may elucidate the particularly low losses observed. As noted in Table VI, page 37, the formation of a glassy boron-bearing reaction product was observed and, presumably, it was of sufficiently low vapor pressure to prohibit significant boron loss from the system.

In all mixtures in which $\mathrm{B}_{2} \mathrm{O}_{3}$ could form, the rate of $\mathrm{B}_{2} \mathrm{O}_{3}$ volatilization was sufficient to account for the observed losses. Boron sesquioxide, held at $1135^{\circ} \mathrm{C}$ for one hour in vacuum, vaporized at a rate of 22 milligrams of $\mathrm{B}_{2} \mathrm{O}_{3}$ per square centimeter of exposed surface of the molten mass per hour. This exceeds the most conservative estimate of boron loss per square centimeter of exposed surface area of any metal oxide compact confirming the feasibility of the proposed Ioss mechanism.

As an alternate loss mechanism, the formation and volatilization of boron monoxide in the manner described by Kanda (24) must be examined. 
Since the simultaneous presence of boron and boron sesquioxide are required, such a reaction may occur only before the bulk of the boron is oxidized to the sesquioxide. Therefore, if it does occur, it probably proceeds for a short time only and is thus inconsequential.

Argon Environment Heat Treatment

High-purity argon, like vacuum, is a neutral atmosphere.

Table VIII summarizes the losses generated in this environment. Table IX Iists, for convenient intercomparison, the average boron losses from each material combination and heat-treatment atmosphere studied. Again, losses experienced by. samples containing pure metal matrices were minimal and not significant. The losses of boron from the metal oxide matrix samples were less than those observed in vacuum, presumably, because the volatilization rate of the boron sesquioxide was reduced by argon atmosphere. The volatilization rate was determined to be 2 milligrams of $\mathrm{B}_{2} \mathrm{O}_{3}$ per square centimeter of exposed surface per hour at $1135^{\circ} \mathrm{C}$ in one atmosphere of argon as compared to 22 milligrams of $\mathrm{B}_{2} \mathrm{O}_{3}$ per hour in vacuum. Thus, these reduced boron losses recorded are consistent with the mechanism previously postulated and described.

Wet Helium Environment Heat Treatment

Helium containing 15,000 parts per million $\mathrm{H}_{2} \mathrm{O}$, that is, a water vapor partial pressure of 18.8 millimeters of mercury, is a considerably different heat-treatment environment than either vacuum or high-purity argon. Thermodynamic calculations (Appendix II) show that a dymamic 
TABLE VIII

BORON LOSSES FROM COMPACTS OF 5 WEIGHT PER CENT BORON HEAT TREATED AT $1135^{\circ} \mathrm{C}$ FOR ONE AND ONE-FOURTH HOURS IN ARGON

\begin{tabular}{|c|c|c|c|c|c|}
\hline \multirow[b]{2}{*}{ Matrix } & \multicolumn{4}{|c|}{ Boron Loss, \% } & \multirow[b]{2}{*}{ Postsinter Appearance } \\
\hline & 1 & 2 & 3 & $\overline{A v}$ & \\
\hline $\mathrm{Si}$ & 3.3 & 4.0 & 2.8 & 3.4 & \\
\hline $\mathrm{SiO}_{2}$ & 9.0 & 9.7 & & 9.1 & \\
\hline $\mathrm{Ni}$ & 5.6 & 5.4 & 4.9 & 5.3 & Nickel-boron alloy formed \\
\hline $\mathrm{NiO}$ & $\% .1$ & 10.2 & & 8.6 & $\begin{array}{l}\text { Nickel oxide redued, nickel- } \\
\text { boron alloy formed }\end{array}$ \\
\hline $\mathrm{Cr}$ & 1.3 & 3.6 & 4.0 & 3.0 & Porous metallic disk \\
\hline $\mathrm{Cr}_{2} \mathrm{O}_{3}$ & 8.4 & 7.8 & & 8.1 & Black porous compact \\
\hline $\mathrm{Fe}$ & 2.6 & 3.5 & 2.8 & 3.0 & Porous metallic disk \\
\hline $\mathrm{Fe}_{2} \mathrm{O}_{3}$ & & & & & $\begin{array}{l}\text { Components reacted, and } \\
\text { splattered }\end{array}$ \\
\hline
\end{tabular}


TABLE IX

AVERAGE BORON LOSSES FROM COMPACTS OF 5 WEIGHT PER CENT BORON HEAT TREATED ONE AND ONE-FOURTH HOURS AT $1135^{\circ} \mathrm{C}$

\begin{tabular}{|c|c|c|c|c|c|c|}
\hline \multirow[b]{2}{*}{ Matrix } & \multicolumn{6}{|c|}{ Heat-Treat Environment } \\
\hline & Vacuum & Argon & $\begin{array}{c}\text { Wet } \\
\text { Helium }\end{array}$ & $<7 \stackrel{\mathrm{H}_{2}}{\mathrm{ppm} \mathrm{H}_{2} \mathrm{O}}$ & 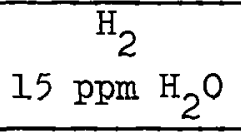 & $\begin{array}{c}\mathrm{H}_{2} \\
460 \mathrm{ppm} \mathrm{H}_{2} \mathrm{O} \\
\end{array}$ \\
\hline $\mathrm{Si}$ & 2.6 & 3.4 & 10.1 & 15.7 & 15.6 & 12.3 \\
\hline $\mathrm{SiO}_{2}$ & 12.3 & 9.1 & 7.2 & & & 70.0 \\
\hline $\mathrm{Ni}$ & 2.6 & 5.3 & 48.2 & 11.7 & 11.8 & 18.0 \\
\hline $\mathrm{NiO}$ & 31.5 & 8.6 & 44.0 & 63.3 & 63.3 & 61.7 \\
\hline $\mathrm{Cr}$ & 1.7 & 3.0 & 7.3 & 8.0 & 8.2 & 7.9 \\
\hline $\mathrm{Cr}_{2} \mathrm{O}_{3}$ & 20.4 & 8.1 & 14.8 & 30.7 & 30.6 & 28.1 \\
\hline $\mathrm{Fe}$ & 5.1 & 3.0 & * & * & * & 14.1 \\
\hline $\mathrm{Fe}_{2} \mathrm{O}_{3}$ & & & * & * & * & * \\
\hline
\end{tabular}


environment at this water vapor level is oxidizing for boron. Thus, with sufficient reaction time, complete boron oxidation and subsequent loss by either $\mathrm{B}_{2} \mathrm{O}_{3}$ volatilization or hydration would be anticipated regardless of the matrix constituent. Observed losses in such an environment are shown in Table X. Several duplicate series of samples were heat treated to verify those losses initially. obselved and are Iisted also. The equivalent losses in the duplicate series demonstrate both experimental reproducibility and validity.

Comparison of the loss data in wet helium with the neutral atmosphere cases (Table IX, page 45) shows that all samples, regardless of the matrix, experienced a significant loss only in the oxidizing environment. This reaffirms the hypothesis that boron oxidation to $\mathrm{B}_{2} \mathrm{O}_{3}$ and subsequent oxide volatilization is the mechanism of boron escape.

However, the total boron loss from any sample was less than calculated based on the amount of oxygen present. Physical factors, similar to those encountered during vacuum sintering, are believed responsible for the discrepancy. For example, both the $\mathrm{B}-\mathrm{Cr}$ and $\mathrm{B}-\mathrm{Cr}_{2} \mathrm{O}_{3}$ samples reacted during heat treatment, but maintained a porous sintered structure characterized by a plethora of surface-connected interparticle passages. Accordingly, the deboronization rate of the compacts depended upon the rate of water vapor diffusion into the compact to react with the boron and the rate of gaseous diffusion of the resulting oxide of boron from the compact. 
TABLE X

BORON LOSSES FROM COMPACTS OF 5 WEIGHT PER CENT BORON

HEAT TREATED AT $1135^{\circ} \mathrm{C}$ FOR ONE AND ONE-FOURTH HOURS

IN WET $\left(15,000\right.$ PARTS PER MILLION $\left.\mathrm{H}_{2} \mathrm{O}\right)$ HELIUM

\begin{tabular}{|c|c|c|c|c|c|c|}
\hline \multirow[b]{2}{*}{ Matrix } & \multicolumn{4}{|c|}{ Boron Loss, \% } & & \multirow[b]{2}{*}{ Postsinter Appearance } \\
\hline & 1 & 2 & 3 & $\overline{A v}$ & & \\
\hline $\mathrm{Si}$ & 11.0 & 8.3 & 11.1 & 10.1 & & \\
\hline $\mathrm{SiO}_{2}$ & 6.5 & 7.5 & 7.6 & 7.2 & & Glassy appearance \\
\hline $\mathrm{Ni}$ & 48.8 & 49.2 & 49.9 & 49.3 & & \\
\hline $\mathrm{Ni}^{*}$ & 46.0 & 48.0 & & 47.0 & \} & Dull metallic button \\
\hline $\mathrm{NiO}$ & 41.2 & 42.7 & 40.6 & 41.5 & & \\
\hline $\mathrm{NiO}^{*}$ & 49.5 & 43.5 & & 46.5 & \} & Dull metallic mass \\
\hline $\mathrm{Cr}$ & 6.8 & 8.3 & 5.4 & 6.8 & & \\
\hline $\mathrm{Cr}^{*}$ & 7.4 & 8.2 & & 7.8 & \} & Black porous disk \\
\hline $\mathrm{Cr}_{2} \mathrm{O}_{3}$ & 13.3 & 20.3 & 20.2 & 17.9 & \} & Green porous disk with black \\
\hline $\mathrm{Cr}_{2} \mathrm{O}_{3}^{*}$ & 10.2 & 13.4 & & 11.7 & & areas \\
\hline
\end{tabular}


In the cases of the nickel and nickel oxide matrices, much larger losses were observed than from the $\mathrm{B}-\mathrm{Cr}$ and $\mathrm{B}-\mathrm{Cr}_{2} \mathrm{O}_{3}$ samples. Examination of the sintered compacts revealed that the nickel oxide had been reduced and that both it and the nickel matrix samples had been partially molten for part of the heat-treatment cycle. The metallic nature of the products for both matrices is not unexpected since nickel oxide is thermodynamically unstable at $1135^{\circ} \mathrm{C}$ in helium containing 15,000 parts per million $\mathrm{H}_{2} \mathrm{O}$. Thus, at the initiation of the heat treatment, a portion of the boron alloyed with the elemental nickel to form a partially molten button and the balance oxidized to $\mathrm{B}_{2} \mathrm{O}_{3}$. Similarly, nickel oxide simultaneously was reduced chemically and thermally. Thereafter, the metallic button coalesced and the liquid boron sesquioxide was excluded from the alloy volume. A portion of the oxidation volatilized and the remainder was absorbed by the porous sintering boat. Scrapings of the sintering boat bottom were found to contain a considerable quantity of boron, supporting the above hypothesis.

Hydrogen Environment Heat Ireatment.

Compositionally identical sets of samples were heat treated in hydrogen of three distinct inlet water vapor contents: less than 7, 15, and 460 parts per million $\mathrm{H}_{2} \mathrm{O}$. Analytically determined boron. Iosses are presented in Tables XI, XII, and XIII, respectively, and the average losses summarized in Table IX, page 45. 


\section{TABLE XI}

BORON LOSSES FROM COMPACTS OF 5 WEIGHT PER CENT BORON HEAT TREATED AT $1135^{\circ} \mathrm{C}$ FOR ONE AND ONE-FOURTH HOURS IN DRY (LESS THAN 7 PARTS PER MILLION $\mathrm{H}_{2} \mathrm{O}$ ) HYDROGEN

\begin{tabular}{lccccl}
\hline & \multicolumn{4}{c}{ Boron Loss, $\%$} & \\
\cline { 2 - 5 } Matrix & 1 & 2 & 3 & Av & Postsinter Appearance \\
\hline $\mathrm{Si}$ & 14.3 & 14.1 & 18.6 & 15.7 & Porous dense disk \\
$\mathrm{Ni}$ & 11.4 & 11.0 & 12.8 & 11.7 & Metallic button \\
$\mathrm{NiO}$ & 50.2 & 69.2 & 70.3 & 63.2 & Metallic button \\
$\mathrm{Cr}$ & 8.8 & 0.6 & 8.8 & 8.0 & Pulvis metillic disk \\
$\mathrm{Cr}_{2} \mathrm{O}_{3}$ & 31.8 & 28.7 & 31.5 & 30.7 & Porous dark disk \\
\hline \hline
\end{tabular}




\section{TABLE XII}

BORON LOSSES FROM COMPACTS OF 5 WEIGHT PER CENT BORON HEAT TREATED AT $1135^{\circ} \mathrm{C}$ FOR ONE AND ONE-FOURTH HOURS IN HYDROGEN CONTAINING 15 PARTS PER MILLION $\mathrm{H}_{2} \mathrm{O}$

\begin{tabular}{lccccl}
\hline & \multicolumn{3}{c}{ Boron Loss, \% } & & Postsinter Appearance \\
\cline { 2 - 5 } Matrix & 1 & 2 & 3 & Av & Porous dark disk \\
\hline $\mathrm{Si}$ & 14.3 & 14.1 & 18.6 & 15.6 & Por \\
$\mathrm{Ni}$ & 11.4 & 11.0 & 1.2 .8 & 11.8 & Metallis button \\
$\mathrm{NiO}$ & 50.2 & 69.2 & 70.3 & 63.3 & Metallic button \\
$\mathrm{Cr}$ & 8.6 & 6.6 & 8.8 & 8.2 & Porous metallic disk \\
$\mathrm{Cr}_{2} \mathrm{O}_{3}$ & 31.8 & 28.7 & 31.5 & 30.6 & Porous dark compact \\
\hline
\end{tabular}


TABLE XIII

BORON LOSSES FROM COMPACTS OF 5 WEIGHT PER CENT BORON

HEAT TREATED AT $1135^{\circ} \mathrm{C}$ FOR ONE AND ONE-FOURTH HOURS

IN HYDROGEN CONTAINING 460 PARTS PER MILLION $\mathrm{H}_{2} \mathrm{O}$

\begin{tabular}{|c|c|c|c|c|}
\hline \multirow[b]{2}{*}{ Matrix } & \multicolumn{3}{|c|}{ Boron Loss, \% } & \multirow[b]{2}{*}{ Postsinter Appearance } \\
\hline & 1 & 2 & $\mathrm{Av}$ & \\
\hline Si & 12.8 & 11.8 & 12.3 & Porous dark disk \\
\hline $\mathrm{SiO}_{2}$ & 70 & 70 & 70 & $\begin{array}{l}\text { Compact covered with } \\
\text { white fuzz }\end{array}$ \\
\hline $\mathrm{Ni}$ & 17.8 & 18.2 & 18 & Metallic button \\
\hline $\mathrm{N} 10$ & 32.2 & 71.2 & 61.7 & Metallic button \\
\hline $\mathrm{Cr}$ & 7.3 & 8.4 & 7.9 & Porous metallic disk \\
\hline $\mathrm{Cr}_{2} \mathrm{O}_{3}$ & 27.2 & 28.9 & 28.1 & Porous dark compact \\
\hline $\mathrm{Fe}$ & 12.6 & 15.5 & 14.1 & Porous metallic disk \\
\hline
\end{tabular}


Consider, in particular, the pure metal matrix compacts. Observed losses are appreciable in all cases. The calculated boron losses, based on the total amount of water available and presuming a boron oxidationvolatilization sequence, are presented in Table XIV. Thermodynamically, the oxidation of boron by water vapor is feasible in these systems as shown in Appendix II. However, this effect was not observed, for the boron losses recorded do not reflect the water content of the heattreating environment. Thus, the effect of water vapor level was of secondary significance.

The largest boron losses from oxide-base compacts were recorded during heat treatment in hydrogen. This cannot be explained by either the rate of $\mathrm{B}_{2} \mathrm{O}_{3}$ volatilization or by incremental increases. of total oxidation in response to the residual water vapor content.

To precisely determine the roll of hydrogen, a singular fragment of arc-melted boron was heated at $1135^{\circ} \mathrm{C}$ in both hydrogen (Iess than 7 parts per million $\mathrm{H}_{2} \mathrm{O}$ ) and helium (less than 7 parts per million $\mathrm{H}_{2} \mathrm{O}$ ). Successive one-hour treatment in the hydrogen resulted in an average weight loss of 7.5 milligrams per hour. No weight losses were observed during the heat treatment in helium. It is therefore believed that, in accordance with the hydrogen-boron reactions previously discussed, significant quantity of boron was lost from the test samples by boron hydrogenation. Attempts to liquid nitrogen cold trap such products were unsuccessful and this is attributed to the thermal decomposition of the volatile boron-hydrogen fragments as catalyzed by the metal furnace muffle. 
TABLE XIV

STOICHIOMEIRIC RELATIONSHIPS FOR THE OXIDATION OF BORON TO $\mathrm{B}_{2} \mathrm{O}_{3}$ BY THE WATER VAPOR INTRODUCED BY THE HYDROGEN SINTERING ATMOSPHERE

\begin{tabular}{|c|c|c|c|}
\hline $\begin{array}{l}\text { Hydrogen Water } \\
\text { Content (ppm) }\end{array}$ & $\begin{array}{l}\text { Total } \mathrm{H}_{2} \mathrm{O} \text { in } \\
\text { Furnace During } \\
\text { Heat Treatment } \\
\text { (moles } \times 10^{4} \text { ) }\end{array}$ & $\begin{array}{l}\text { Oxygen* Excess } \\
\left(\text { moles } x \quad 10^{4}\right)\end{array}$ & $\begin{array}{c}\text { Boron Loss** } \\
\text { (theoretical } \\
\text { maximum \%) }\end{array}$ \\
\hline 460 & 145 & +124 & 71 \\
\hline 15 & 21.6 & 0 & 10.7 \\
\hline 7 & 2.2 & -19 & 1.1 \\
\hline
\end{tabular}

* Based on an average boron loss of 10 per cent each from three compacts or $14 \times 10^{-4}$ moles of boron.

${ }^{*}$ Three compacts per set or $135 \times 10^{-4}$ moles of boron originally present. 
Compacts of 5 weight per cent boron dispersed in nickel were heat treated at $1135^{\circ} \mathrm{C}$ for $20,40,60$, and 75 minutes in hydrogen (less than 7 parts per million $\mathrm{H}_{2} \mathrm{O}$ ). Equivalent losses of $9.5,10.3,9.7$, and 11.7 per cent, respectively, were determined. Thus after a rapid initial loss, the loss rate decreased presumably due to the reduced sample area available for gas-boron reaction. Figure 10, a photomicrograph of a typical nickel-boron compact heat treated 75 minutes in hydrogen, illustrates that the sample fused during heat treatment and, correspondingly, thereafter possessed a low total surface area.

However', losses from boron-chromium samples would be controlled by the rate of reactant permeation and product removal from the sample confines due to the porous nature of the heat-treated compacts; shown. in Figure 11.

\section{EXAMINATION OF DEBORONIZATION KINENICS}

Powder Metal System

The determination of the effect of hydrogen dew point and flow rate and sintering time on the boron loss experienced by five-gram compacts of -100 mesh, 0.25 weight per cent boron-stainless steel alloy powder (master alloy) heat treated at $1135^{\circ} \mathrm{C}$ served to evaluate both the effect of the aforementioned variables and the kinetics of boron loss from powder systems. Master alloy compacts were pressed at 33 tons per square inch into an 0.500 inch diameter right cylinder configuration and sintered in hydrogen of three different water contents 


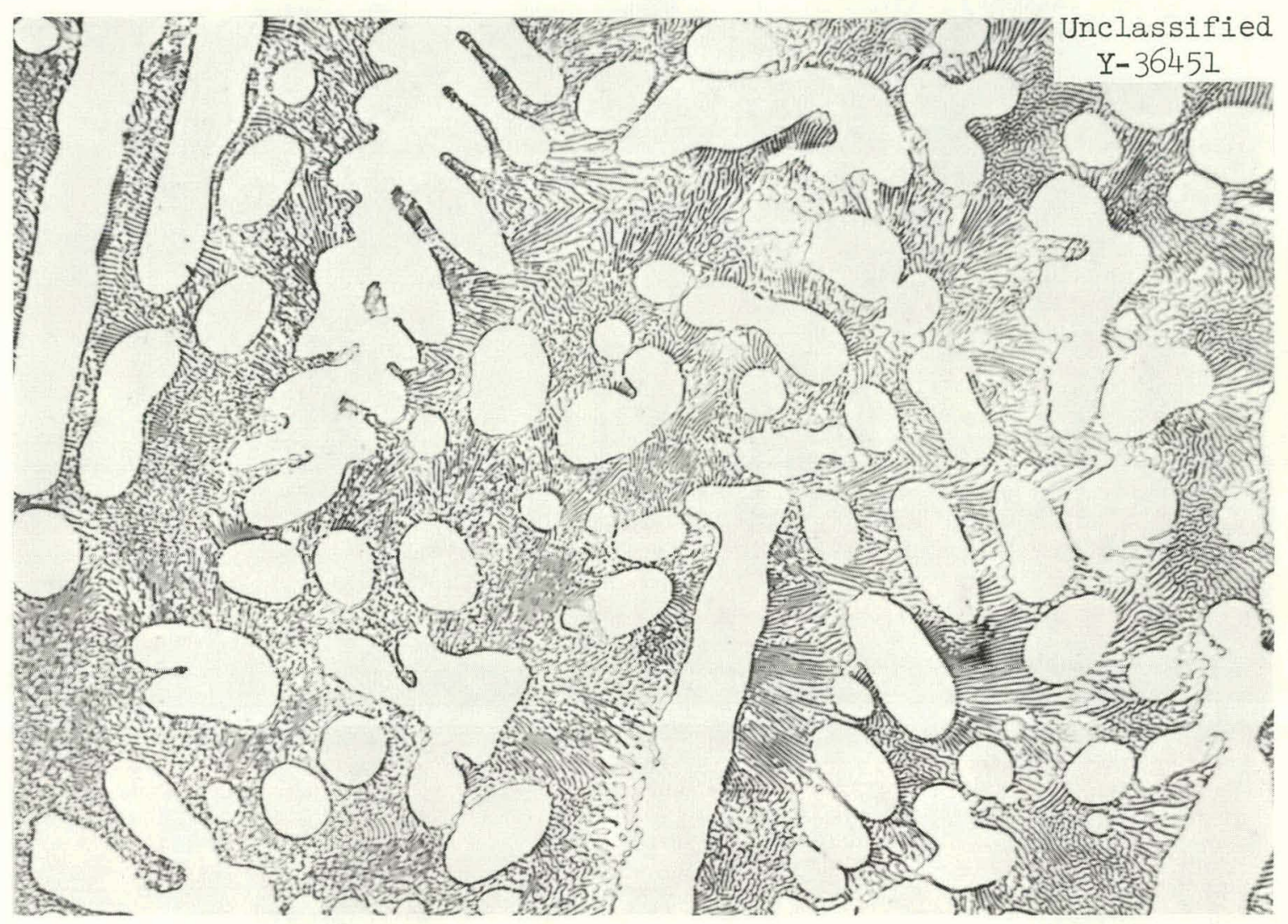

Figure 10. Microstructure of a five per cent boron-nickel compact sintered 75 minutes at $1135^{\circ} \mathrm{C}$ in dry hydrogen. Structurally, primary alpha nickel is surrounded by a matrix of eutectic nickel boride and nickel. Etchant: $92 \mathrm{HCl}_{-}-3 \mathrm{HNO}_{3}-\mathrm{H}_{2} \mathrm{SO}_{4}$ (volume per cent). 500X. 

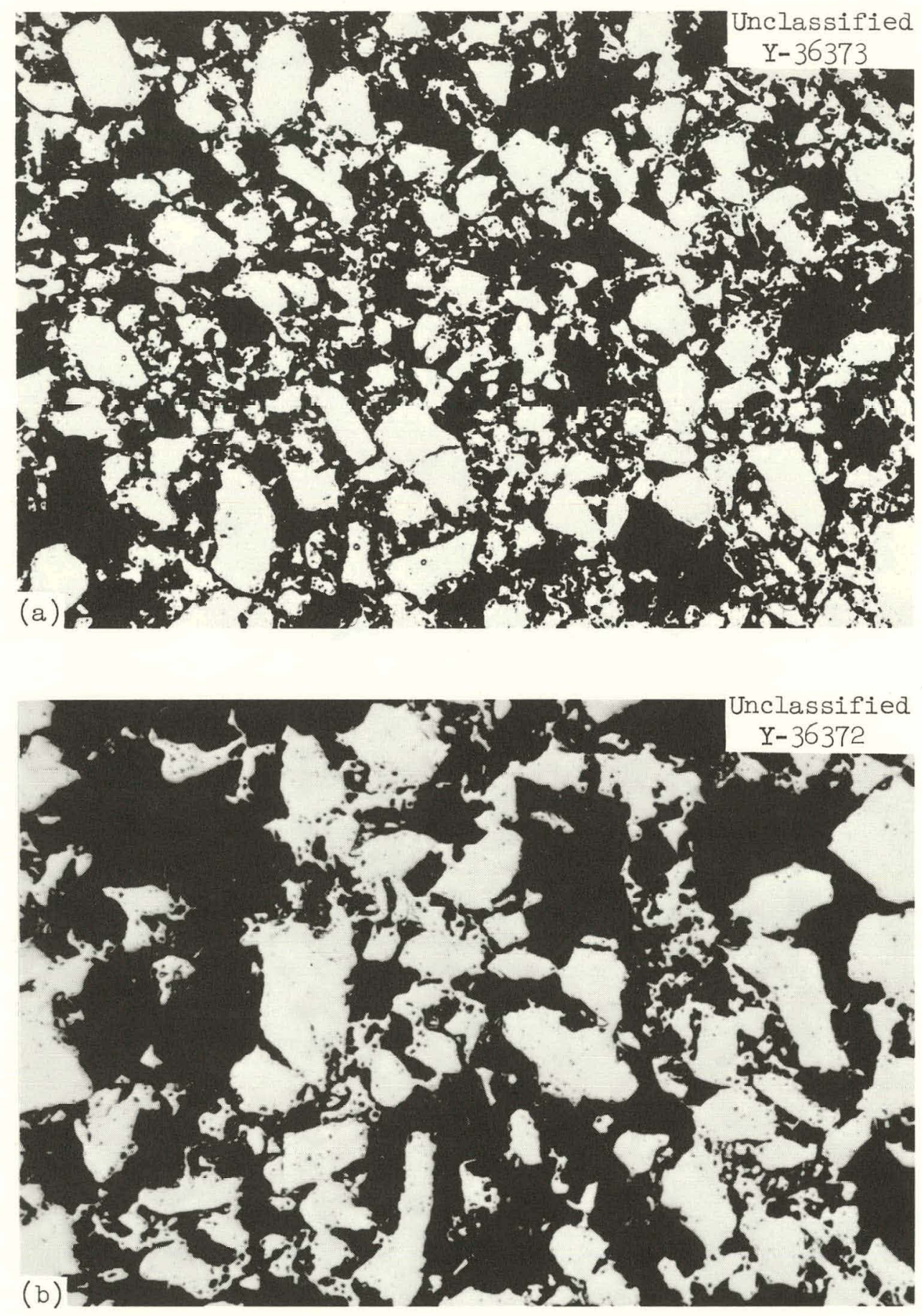

Figure 11. Cross section of a compact originally containing five per cent boron dispersed in chromium, sintered in hydrogen (460 parts per million $\mathrm{H}_{2} \mathrm{O}$ ) for one and one-fourth hours at $1135^{\circ} \mathrm{C}$, showing the large amount of interconnected porosity (black areas). As polished. (a) $250 \mathrm{X}$ (b) 500X. 
(approximately 1, 100, and 460 parts per million water vapor) and two flow rates (20 and 40 cubic feet per hour) for times varying from onefourth to sixteen hours. Losses experienced by individual compacts are listed in Appendix III and the arithmetic average loss graphically presented, in Figure 12, as a function of the square root of heattreatment time for constant sintering environment.

The boron loss-time relationships for all sample series heat treated in a given environment were initially equivalent and could be described as:

$f_{d}=m t^{1 / 2}+k$

where

$f_{\mathrm{d}}=$ fractional boron depletion, $t=$ sintering time in hours, and

$\mathrm{m}$ and $\mathrm{k}$ are constants.

The values of $\mathrm{m}$ and $\mathrm{k}$ are listed in Table XV. However, after approximately seven hours at temperature, the rate of deboronization of those sample groups heat treated in the wetter environments (100 and 460 parts per million $\mathrm{H}_{2} \mathrm{O}$ ) decreased from that predicted by the parabolic relationship. A similar decrease was experfenced after two hours by those sintered in hydrogen (approximately one part per million $\mathrm{H}_{2} \mathrm{O}$ ). To clarify this behavior, the effect of the total compact surface area, as defined by the BET measurement method (3I) on the rate of boron loss, was determined. 


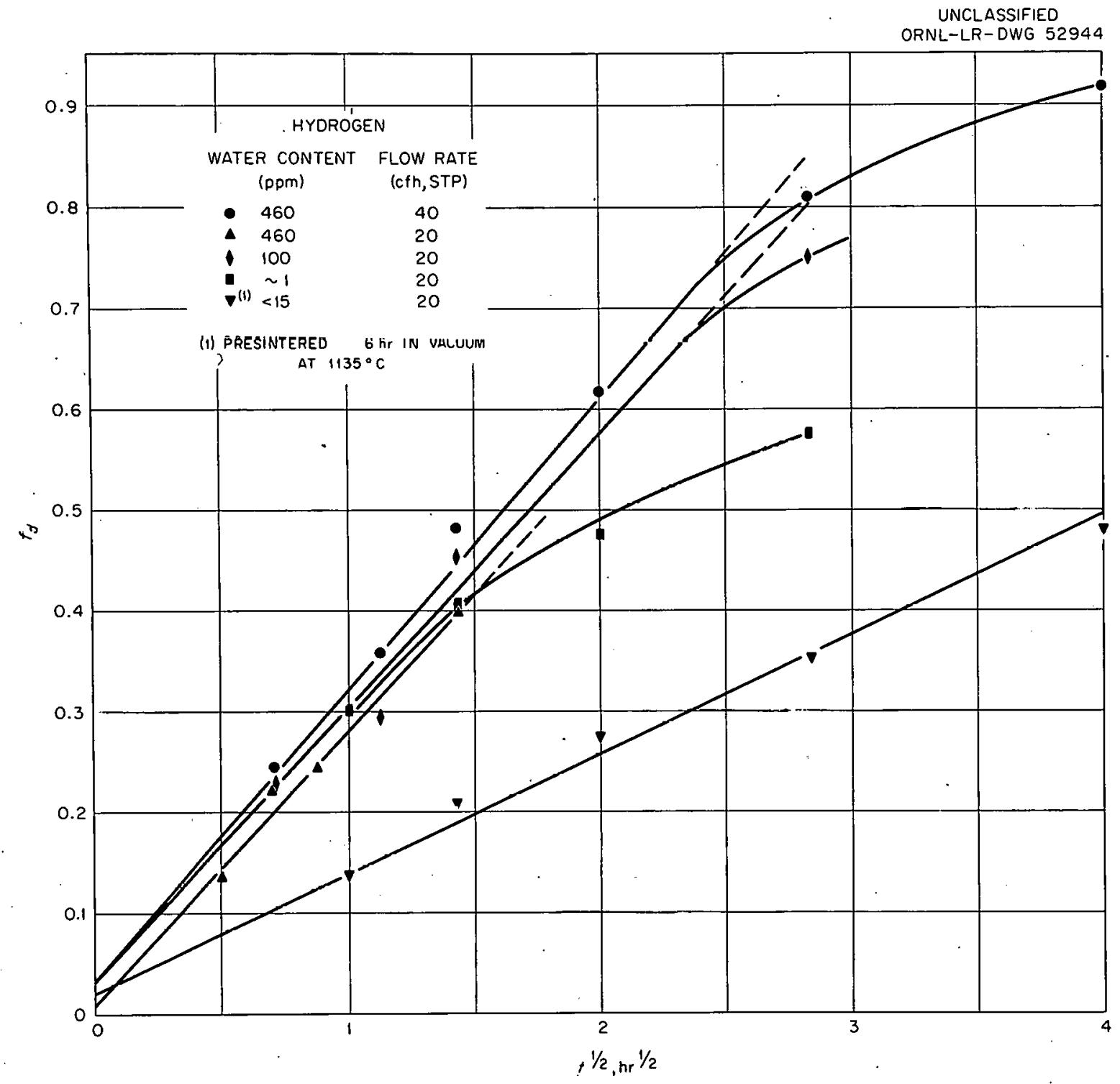

Figure 12. Fraction boron depletion, $f d$, as a function of the square root of sintering time from powder metallurgically prepared 5-gram compacts of 0.25 weight per cent boron-stainless steel alloy sintered in hydrogen. 
TABLE XV

EMPIRICAL ANALYTICAL RELATIONSHIPS OF FRACTIONAL BORON DEPLETION AS A FUNCTION OF HEAT-TREATING TIME OF POWDER COMPACTS SINTERED AT

$1135^{\circ} \mathrm{C}$ IN HYDROGEN OF VARYING WATER CONTENT AND FLOW RATES

\begin{tabular}{ccccc}
\hline $\begin{array}{c}\text { Hydrogen } \\
\text { Water } \\
\begin{array}{c}\text { Content } \\
\text { (ppm) }\end{array}\end{array}$ & $\begin{array}{c}\text { Hydrogen } \\
\text { Flow Rate } \\
\text { (CFH, STP) }\end{array}$ & $\begin{array}{r}\text { Fractional Boron Depletion as } \\
\text { a. Function of Time }(\mathrm{hr})\end{array}$ & $\begin{array}{c}\text { Maximum } \\
\text { Time } \\
\text { Investigated } \\
(\mathrm{hr})\end{array}$ \\
\hline 460 & 40 & $f_{\mathrm{d}}=0.285 \mathrm{t}^{\frac{1}{2}}+0.034$ & $0<\mathrm{t}<7 \mathrm{hr}$ & 16 \\
460 & 20 & $f_{\mathrm{d}}=0.255 t^{\frac{1}{2}}+0.002$ & $0<t<2 \mathrm{hr}$ & 2 \\
100 & 20 & $f_{\mathrm{d}}=0.259 t^{\frac{1}{2}}+0.034$ & $0<t<7 \mathrm{hr}$ & 8 \\
1 & 20 & $f_{\mathrm{d}}=0.3 t^{\frac{1}{2}}+\mathrm{k}$ & $0<t<2 \mathrm{hr}$ & 8 \\
$15^{*}$ & 20 & $f_{\mathrm{d}}=0.119 t^{\frac{1}{2}}+0.017$ & $0<t<16 \mathrm{hr}$ & 16 \\
\hline
\end{tabular}

*Presintered six hours in vacuum 
The surface areas of compacts of' t'ive grams each of -100 mesh, boron-free, type 304L stainless steel powder, "green" pressed at 33 tons per square inch into an 0.502 inch diameter right cylinder, were determined as a function of sintering time in dry (approximately one part per million $\mathrm{H}_{2} \mathrm{O}$ ) hydrogen. The rate of surface area decrease, measured from a plot of surface area versus time, is presented graphically in Figure 13. Both the surface area and the rate of surface area decrease undergo a rapid initial decrease and thereafter approach a constant value asymptotically. However, despite the large reduction of compact surface area after eight hours of sintering, the determined area, 250 square centimeters, is a factor of 100 greater than the calculated surface area of the compact at 100 per cent densitication.

The rates of deboronization of master alloy compacts at a given heat-treatment time are included in Figure 13. The plots of the rate of surface area reduction of stainless steel compacts and the rate of deboronization of master alloy compacts, both heat treated in dry (approximately one part per million vapor) hydrogen, are essentially parallel and each converges to a constant value after a total of two hours at temperature.

This relationship suggests three deboronization rate-controlling sequences: (1) the rate of boron reaction with the environment, (2) the rate of gaseous diffusion of the reactant into and reaction product out of the compact via surface-connected porosity, and (3) the rate of solid-state diffusion of boron to both the external and internal metal-atmosphere interfaces. 
UNCLASSIFIED

ORNL-LR-DWG 51993

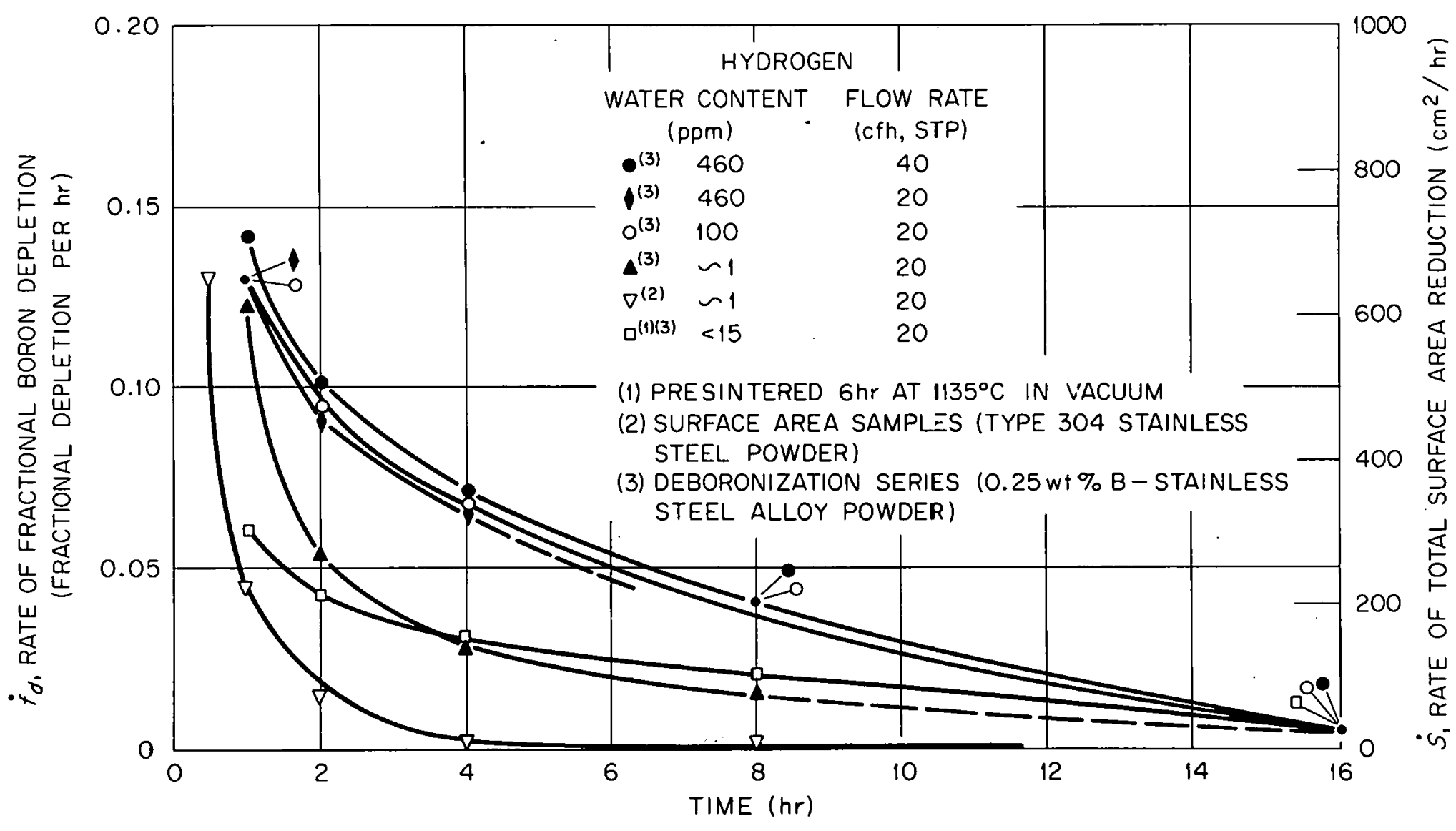

Figure 13. Rate of fractional boron depletion and rate of surface area reduction versus heat-treating time for powder metallurgically prepared samples heat treated in hydrogen at $1135^{\circ} \mathrm{C}$. 
The boron loss experienced by compacts of 5 weight per cent boron mechanically dispersed in pure metal matrices, heat treated in hydrogen for one and one-fourth hours, indicates that the rate of reaction is sufficiently larger than that observed from the master alloy compacts to qualitatively eliminate the reaction rate hypothesis (1).

The morphology of a master alloy compact sintered two hours is shown in Figure 14. While a large amount of porosity is evident, the associated channels are narrow and consequently restricting to gaseous diffusion. Evidently then, reactants can penetrate into and reaction products exit from the compact only with difficulty.

In order to minimize the effect of changing surface area on the rate of boron loss, "green" compacts were sintered six hour's at $1135^{\circ} \mathrm{C}$ in vacuum prior to deboronization in hydrogen. The vacuum heat treatment does not result in deboronization although considerable compact sintering is realized $(32,33)$. It was anticipated that by decreasing the compact surface area by vacuum sintering, further area reduction during deboronization in hydrogen would be negligible. Experimental results of such a series heat treated at $1135^{\circ} \mathrm{C}$ in dry (Iess than 15 parts per million $\mathrm{H}_{2} \mathrm{O}$ ) hydrogen are presented in Table XVI. The boron fractional depletion versus time is shown graphically in Figure 12, page 58 , and can be expressed analytically as $f_{d}=0.120 t^{1 / 2}+0.017$

for sintering times to sixteen hours. Thus, the reduction of both absolute loss and loss rate with time was realized as predicted. 


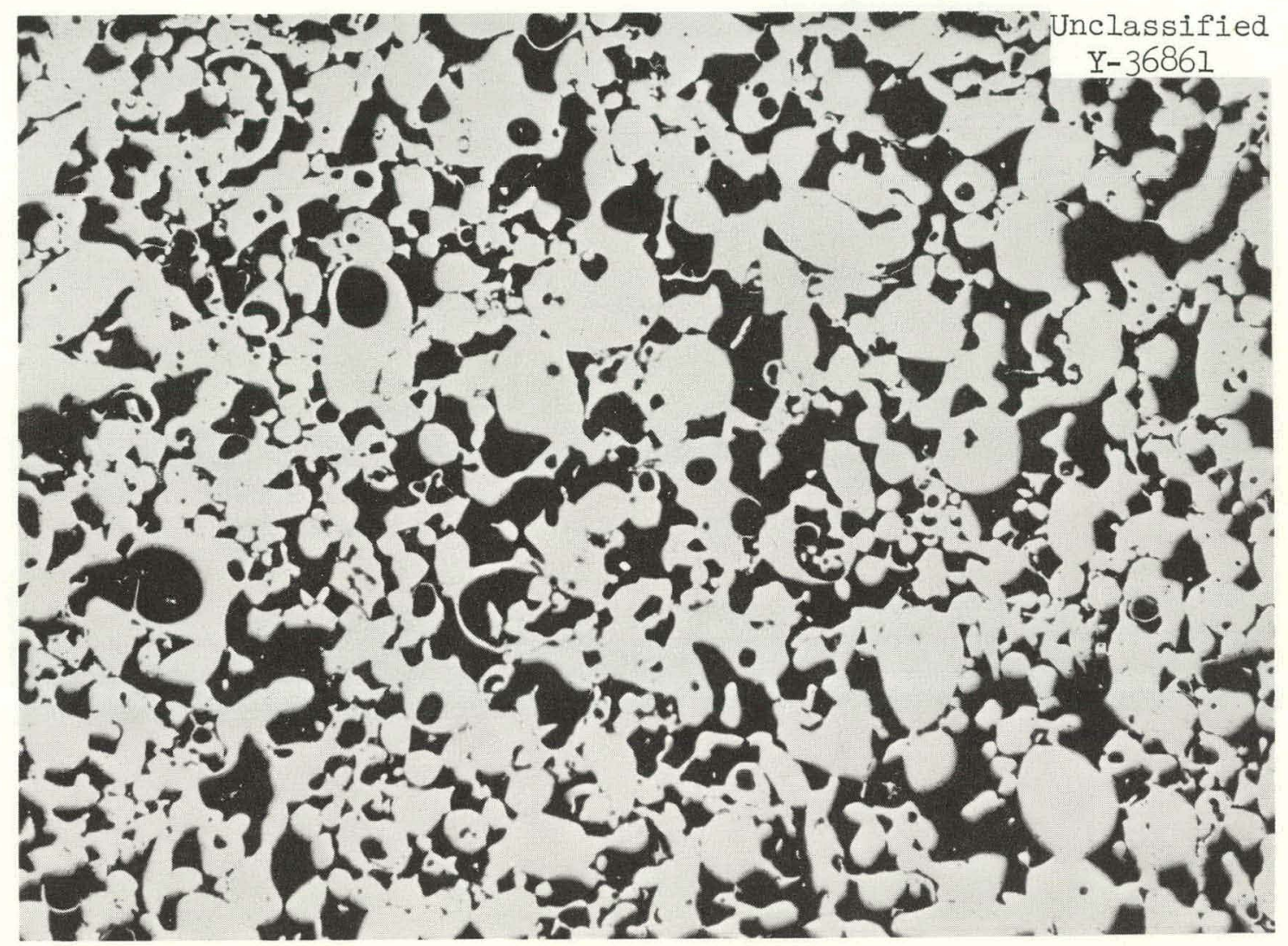

Figure 14. Minus 100 mesh, 0.25 weight per cent boron-stainless steel alloy powder pressed at 33 tons per square inch and sintered two hours at $1135^{\circ} \mathrm{C}$ in hydrogen ( 460 parts per million $\mathrm{H}_{2} \mathrm{O}$ ) showing interconnected porosity. As polished. 100X. 
TABLE XVI

BORON LOSSES FROM 5-GRAM MASTER ALLOY COMPACTS SINTERED IN VACUUM FOR 6 HOURS AT $1135^{\circ} \mathrm{C}$ PRIOR TO HYDROGEN SINTERING (LESS THAN 15 PARTS PER MILLION $\mathrm{H}_{2} \mathrm{O}, 20$ CUBIC FEET PER HOUR) AT $1135^{\circ} \mathrm{C}$

\begin{tabular}{|c|c|c|c|c|c|}
\hline Sample & $\begin{array}{l}\text { Sintering Time } \\
\text { in Hydrogen (hr) }\end{array}$ & $\begin{array}{l}\text { Average } \\
\text { Content }\end{array}$ & $\begin{array}{l}\text { Boron } \\
\text { (mg) }\end{array}$ & $\begin{array}{l}f_{d},{ }^{* *} \\
\text { Boron }\end{array}$ & $\begin{array}{l}\text { Fractional } \\
\text { Depletion }\end{array}$ \\
\hline E 321 & 0 & 12.1 & - & & -- \\
\hline$\exists 322$ & $\perp$ & 10.5 & & & 0.13 \\
\hline E 323 & 1 & 10.5 & & & 0.13 \\
\hline E 324 & 2 & 9.5 & & & 0.22 \\
\hline E 325 & 2 & 9.7 & & & 0.20 \\
\hline E 326 & 4 & 8.7 & & & 0.28 \\
\hline E 327 & 4 & 8.9 & & & 0.26 \\
\hline E 328 & 8 & 7.6 & & & 0.37 \\
\hline E 329 & 8 & 8.2 & & & 0.32 \\
\hline E 330 & 16 & 6.1 & & & 0.50 \\
\hline E 331 & 16 & 6.5 & & & 0.47 \\
\hline
\end{tabular}

* Average of three samples

${ }^{* *} f_{a}=\frac{12.1-M g B \text { present }}{12.1}$ 
If the vacuum-sintered compact is considered a close-packed array of metallic spheroids of constant radius and if solid-state diffusion is the controlling loss factor, the rate of fractional boron depletion upon heat treatment in hydrogen is 0.38 second $^{-1}$ at $t=1$ second as calculated in Appendix IV. Experimentally, an average fractional depletion rate was observed to be $4 \times 10^{-5}$ per second ( $0<t<$ hour), a factor of $10^{4}$ less than that calculated. Therefore, solid-state diffusion is not the rate-controlling loss factor.

The boron-loss rates as a function of time in all of the sintering environments considered are included in Figure 13, page 61. All, independent of environment, converge asymptotically to essentially the same value; however, the rate of approach differs considerably. If the sample surface area controls the rate of loss, the data plotted on Figure 13, page 61, suggest that sintering rate decreases as the water content of the sintering atmosphere increases. This was experimentally demonstrated. The specific surtace area of master alloy compacts, pressed at 30 tons per square inch and sintered at $1135^{\circ} \mathrm{C}$ for four hours in hydrogen (one part per million $\mathrm{H}_{2} \mathrm{O}$ ), was 166 square centimeters per gram; in hydrogen (460 parts per million $\mathrm{H}_{2} \mathrm{O}$ ), 2/40 square centimeters per gram. Physically, the effect of the water content of the hydrogen on sintering rate is probably related to the reduction of the oxide skin originally enveloping each metal particle. The water content of hydrogen in equilibrium with silicon dioxide and chromium sesquioxide at $1135^{\circ} \mathrm{C}$ is 3.5 and 300 parts per million, respectively (34). 
Thus, the postulated oxide skins can be completely reduced only in the driest hydrogen and, thermodynamically, oxidation can proceed in hydrogen containing 460 parts per million $\mathrm{H}_{2} \mathrm{O}$. It is reasonable to suppose that a persisting oxide would hinder sintering as compared to an oxide-free situation.

Apparently then, the rate of deboronization of master alloy compacts is controlled by the rate of gaseous diffusion of reactants and reaction products into and out of the compact. However, the rate of boron loss varies with time while the diffusivity of the boronbearing gaseous species is constant. Therefore, since the rate of boron loss is proportional to the total compact surface area at any time, it, in turn, is presumably proportional to the number and size of open channels permeating the sample. Reducing the number and size of the channels, that is, compact sintering, would therefore reduce the net rate of diffusion of reaction products out of the sample.

\section{DEBORONIZATION OF SHEET SPECIMENS}

Deboronization of a wrought stainless stcel sheet containing 0.128 weight per cent boron presents a considerably ditierent physical situation than that of the master alloy powder compacts by virtue of the former's constant surface area and structure. However, prior to deboronization, both were metallurgically similar, that is, a two-phase structure of an intermetallic boride dispersed in a matrix of interstitial solid solution of boron in austenite. The microstructure of a 
wrought specimen prior to deboronization is illustrated in Figure 15. The intermetallic borides, probably $(\mathrm{Fe}, \mathrm{Cr})_{2} \mathrm{~B}$, are stringered parallel to the rolling direction, but are homogeneously distributed throughout the matrix on a macroscopic scale.

The boron contents of rectangular coupons, approximately 0.512 inch by 0.764 inch by 0.078 inch thick, of the wrought 0.128 weight per cent boron-stainzess steel alloy after heat treatment in hydrogen (less than 15 parts per million $\mathrm{H}_{2} \mathrm{O}$ ) for times to sixteen hours are listed in Table XVII. Figure 16 includes a plot of the same data as the average fractional boron depletion versus the square root of the deboronization time. Also plotted are the losses calculated (Appendix I) on the basis of the total specimen surface area and depth of the metallographically measured deboronized layer. The calculated values fall below those experimentally determined primarily due to the end effects inherent by the sample geometry. However, both relationships are parabolic with time indicating the solid-state diffusion is the loss rate-controlling factor.

The microstructures typical of wrought specimens deboronized 1, 2, 4, 8, and 16 hours are shown in Figures 17, 18, 19, 20, and 21, respectively. In each instance, a deboronized single-phase layer surrounds a two-phase volume.

The depth of the deboronized layer associated with the side of the specimen adjacent to the heat-treating boat during heat treatment was invariably less than that of the opposite surface which was 


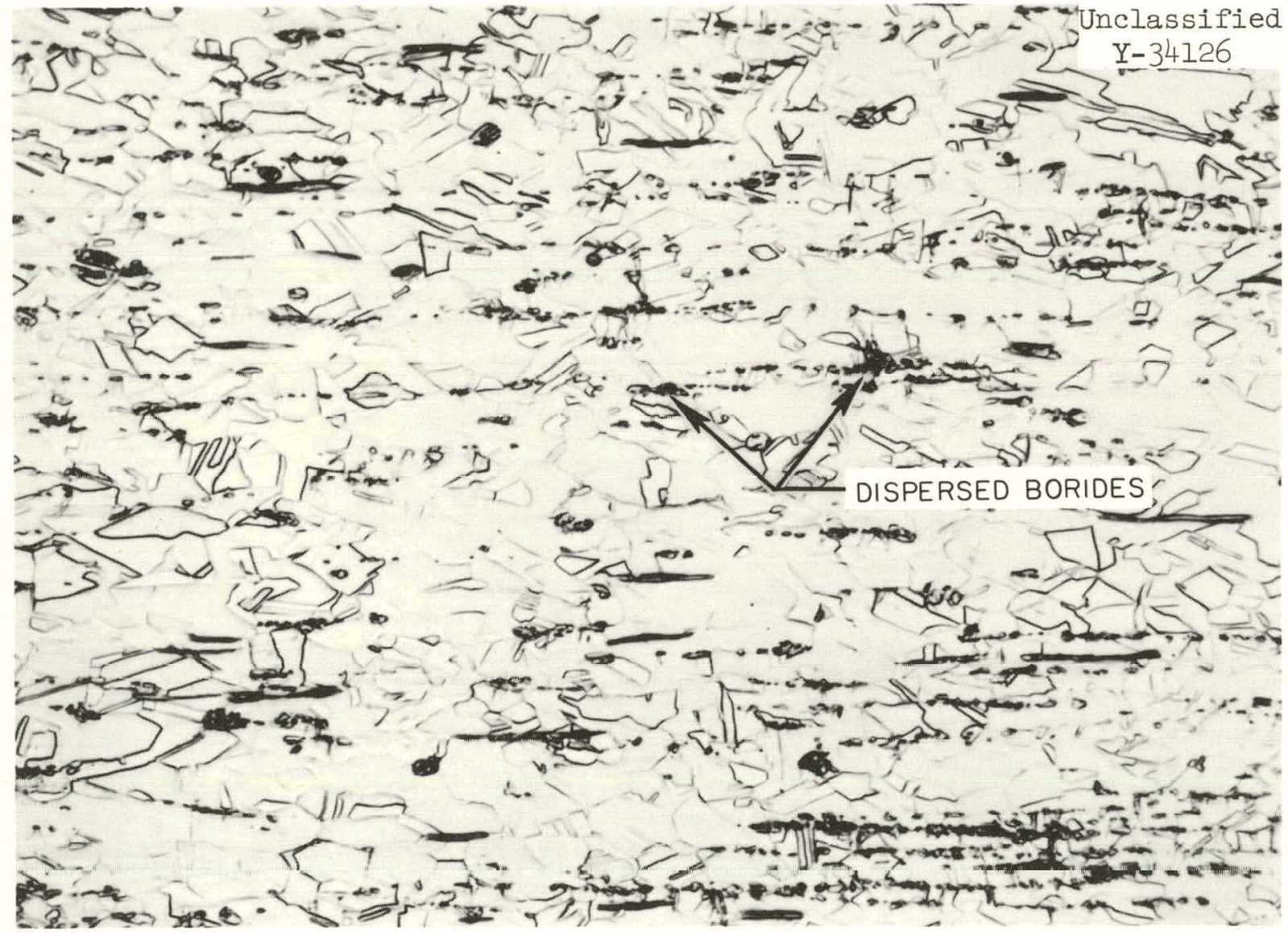

Figure 15. Homogenized stainless steel-0.128 weight per cent boron alloy, prior to heat treatment in hydrogen, showing metallic borides dispersed in a matrix of austenitic stainless steel.

Etchant: Glyceria regia. 500x. 
TABLE XVII

BORON CONTENT OF DEBORONIZED SECTIONS OF WROUGHT 0.128 WEIGHT PER CENT BORON-STAINLESS STEEL ALLOY HEAT TRFATED IN HYDROGEN

(LESS THAN 15 PARTS PER MILLION $\mathrm{H}_{2} \mathrm{O}$ ) AT $1135^{\circ} \mathrm{C}$

\begin{tabular}{|c|c|c|c|}
\hline $\begin{array}{c}\text { Sample } \\
\text { Designation }\end{array}$ & $\begin{array}{c}\text { Deboronization } \\
\text { Time (hr) }\end{array}$ & $\begin{array}{c}\text { Boron }{ }^{*} \text { Content } \\
(\text { wt } \%)\end{array}$ & $\begin{array}{l}\text { Average Boron } \\
\text { Content (wt \%) }\end{array}$ \\
\hline 334 & 1 & 0.105 & \multirow{3}{*}{0.106} \\
\hline & & & \\
\hline 335 & 1 & $0.10^{\prime} 7$ & \\
\hline 336 & 2 & 0.086 & \multirow{3}{*}{0.092} \\
\hline & & & \\
\hline 337 & 2 & 0.098 & \\
\hline 339 & 4 & 0.082 & \multirow{3}{*}{0.084} \\
\hline & & & \\
\hline 340 & 4 & 0.086 & \\
\hline 342 & 8 & 0.068 & \multirow{3}{*}{0.068} \\
\hline & & & \\
\hline 343 & 8 & 0.068 & \\
\hline 359 & 8 & 0.058 & \multirow{3}{*}{0.058} \\
\hline & & & \\
\hline 360 & 8 & 0.058 & \\
\hline 345 & 16 & 0.028 & \multirow{3}{*}{0.0305} \\
\hline $3 / 6$ & 76 & & \\
\hline 346 & 16 & 0.033 & \\
\hline
\end{tabular}

*Analytically determined. 


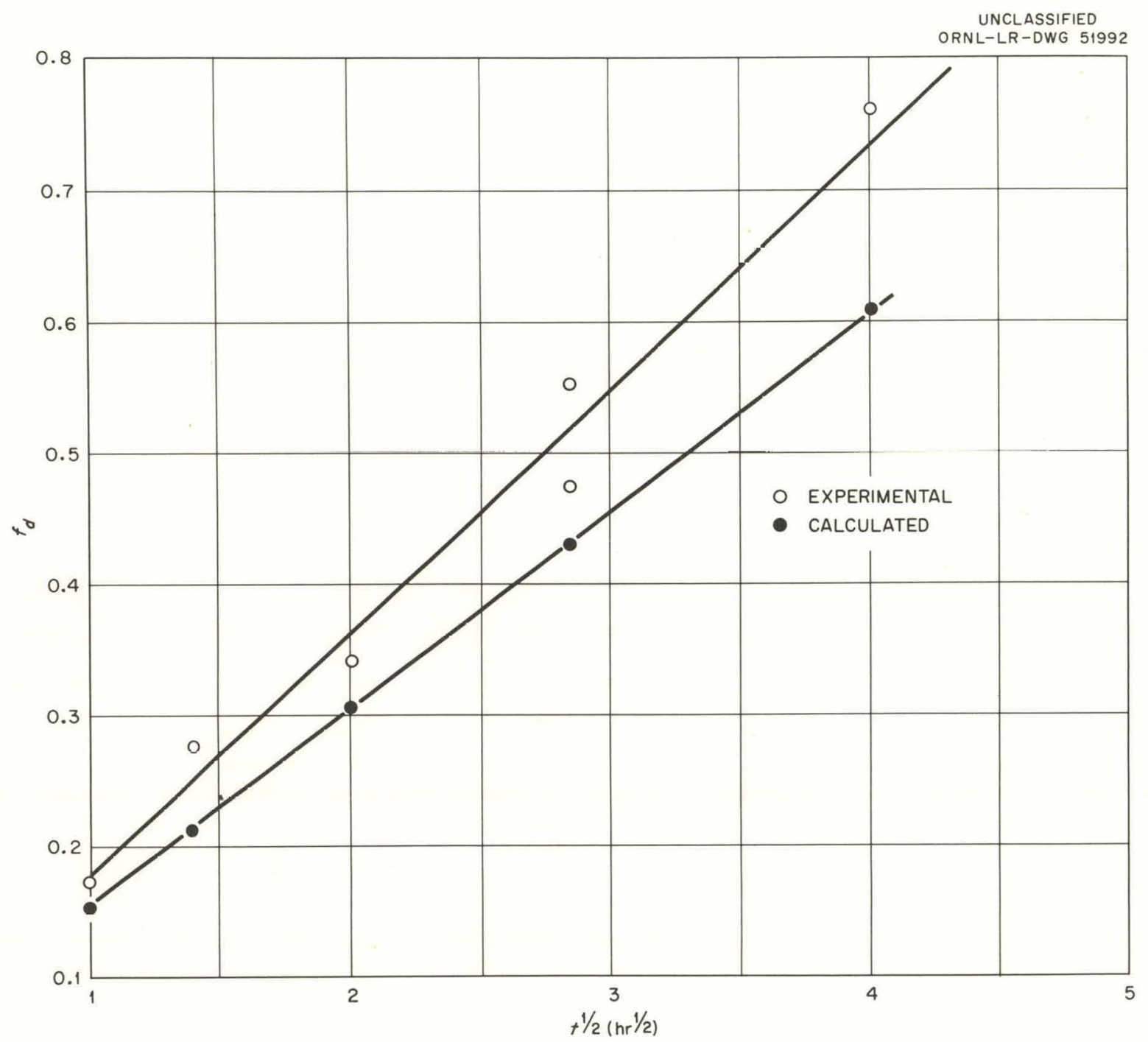

Figure 16. Tractional deboronization versus the square root of the sintering time for samples of 0.128 weight per cent boron-stainless steel alloy heat treated in hydrogen at $1135^{\circ} \mathrm{C}$. 

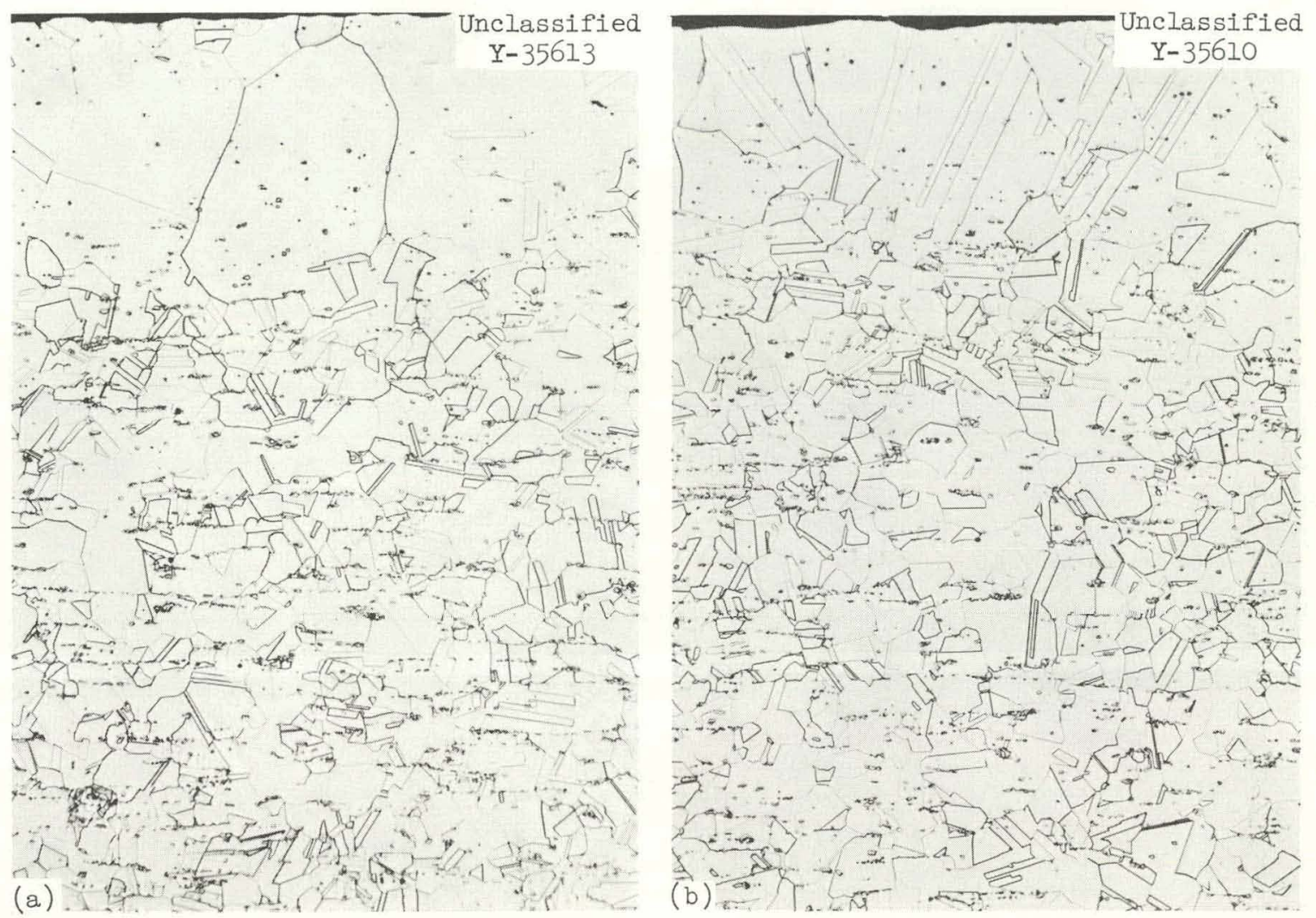

Figure 17. Austenitic stainless steel-0.128 weight per cent boron alloy heat treated for one hour at $1135^{\circ} \mathrm{C}$ in hydrogen.

(a) Maximum deboronized depth and (b) minimum deboronized depth. Etchant: Glyceria regia. 200X. 

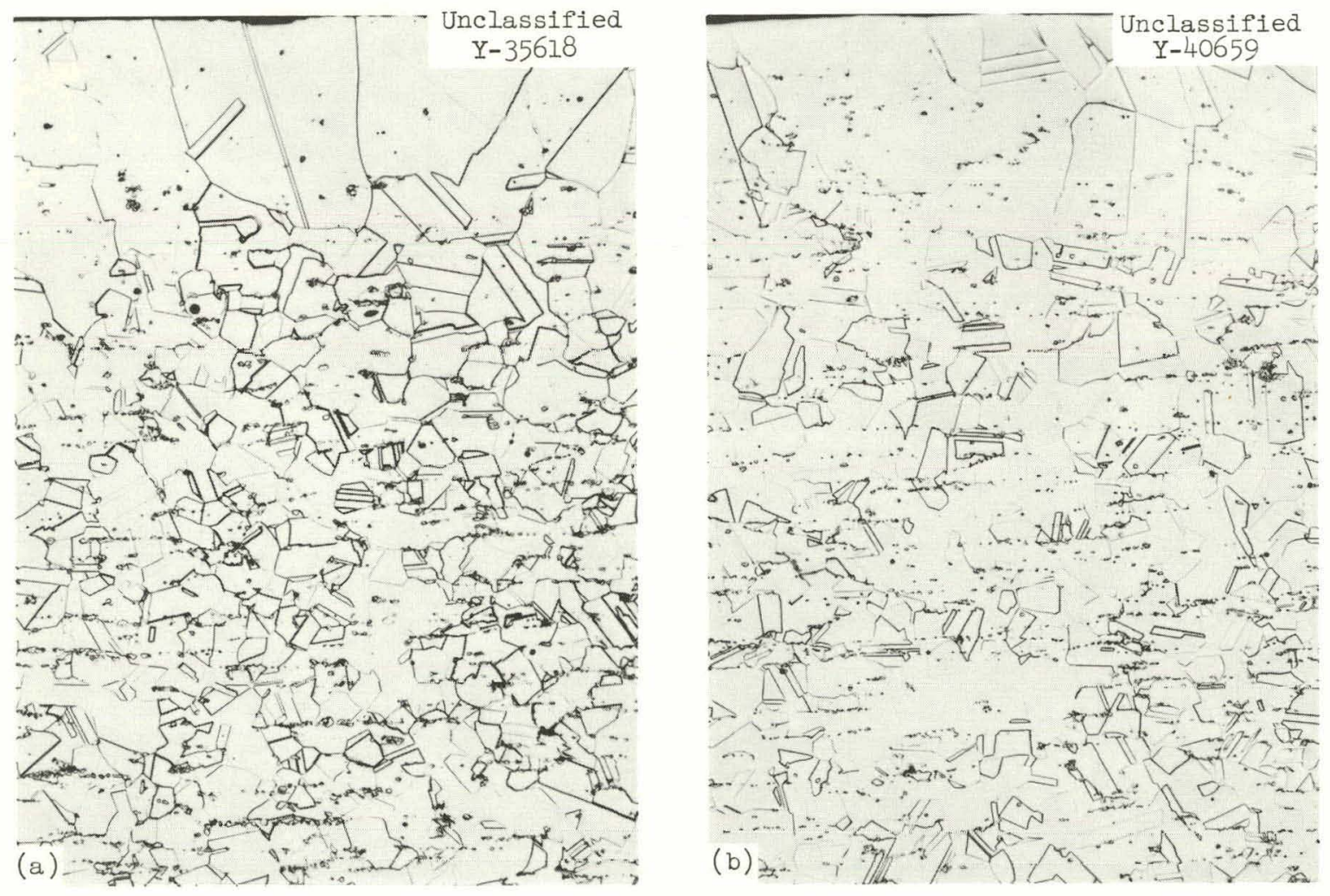

Figure 18. Austenitic stainless steel-0.128 weight per cent boron alloy heat treated for two hours at $1135^{\circ} \mathrm{C}$ in hydrogen.

(a) Maximum deboronized depth and (b) minimum deboronized depth. Etchant: Glyceria regia. 200X. 

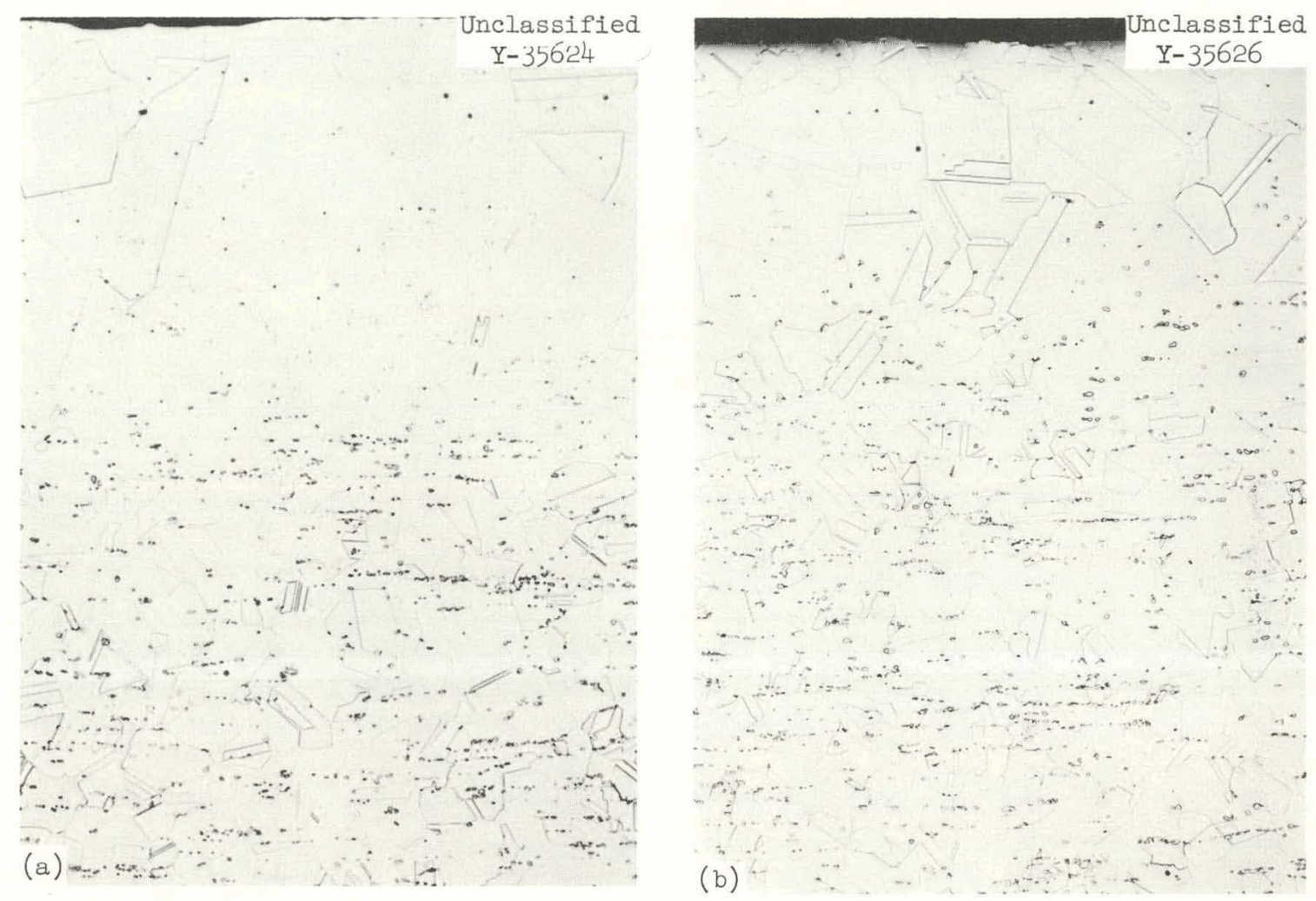

Figure 19. Austenitic stainless steel-0.128 weight per cent boron alloy heat treated for four hours at $1135^{\circ} \mathrm{C}$ in hydrogen. (a) Maximum deboronized depth and (b) minimum deboronized depth. Etchant: Glyceria regia. 200X. 

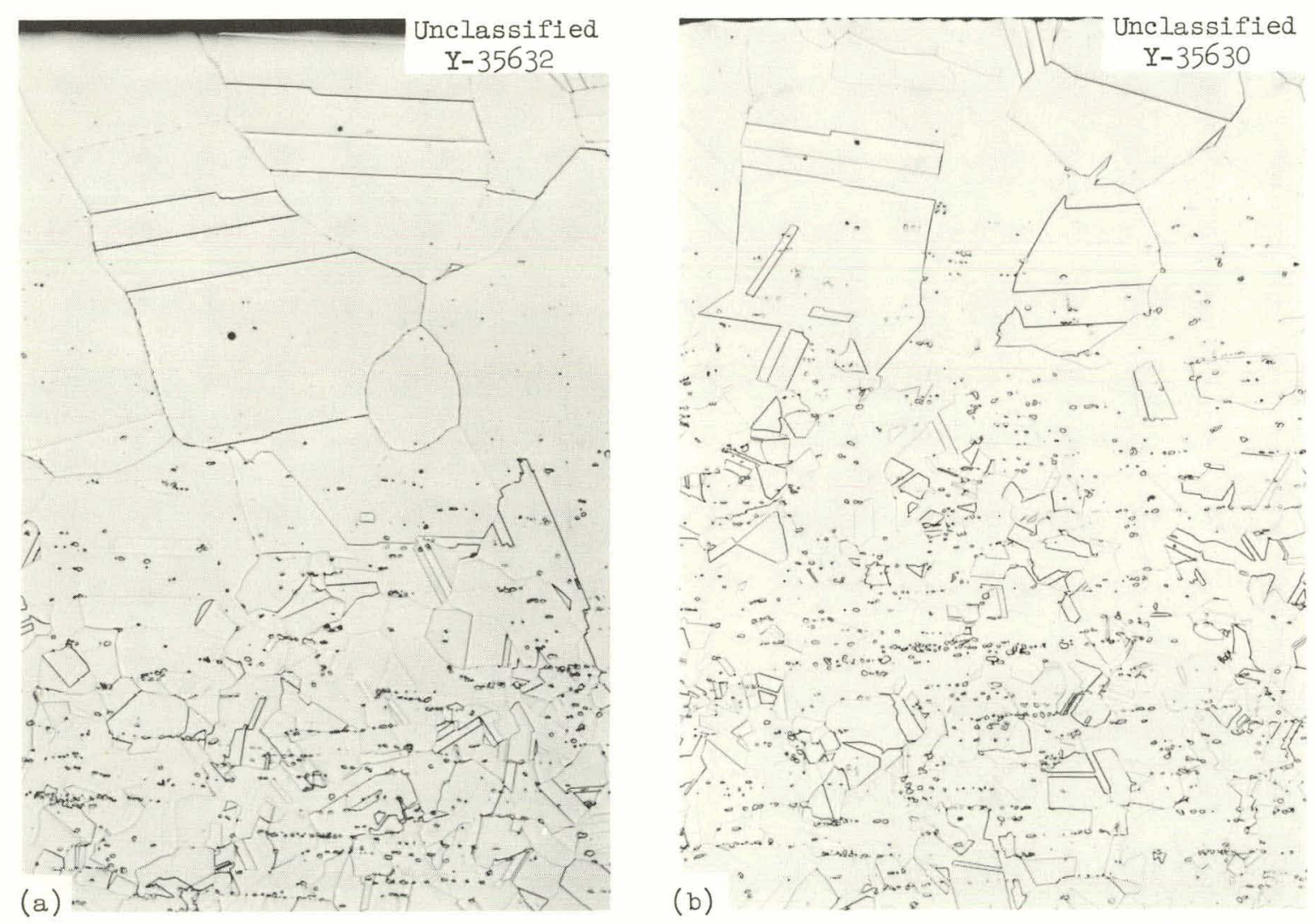

Figure 20. Austenitic stainless steel-0.128 weight per cent boron alloy heat treated for eight hours at $1135^{\circ} \mathrm{C}$ in hydrogen. (a) Maximum deboronized depth and (b) minimum deboronized depth. Etchant: Glyceria regia. 200X. 

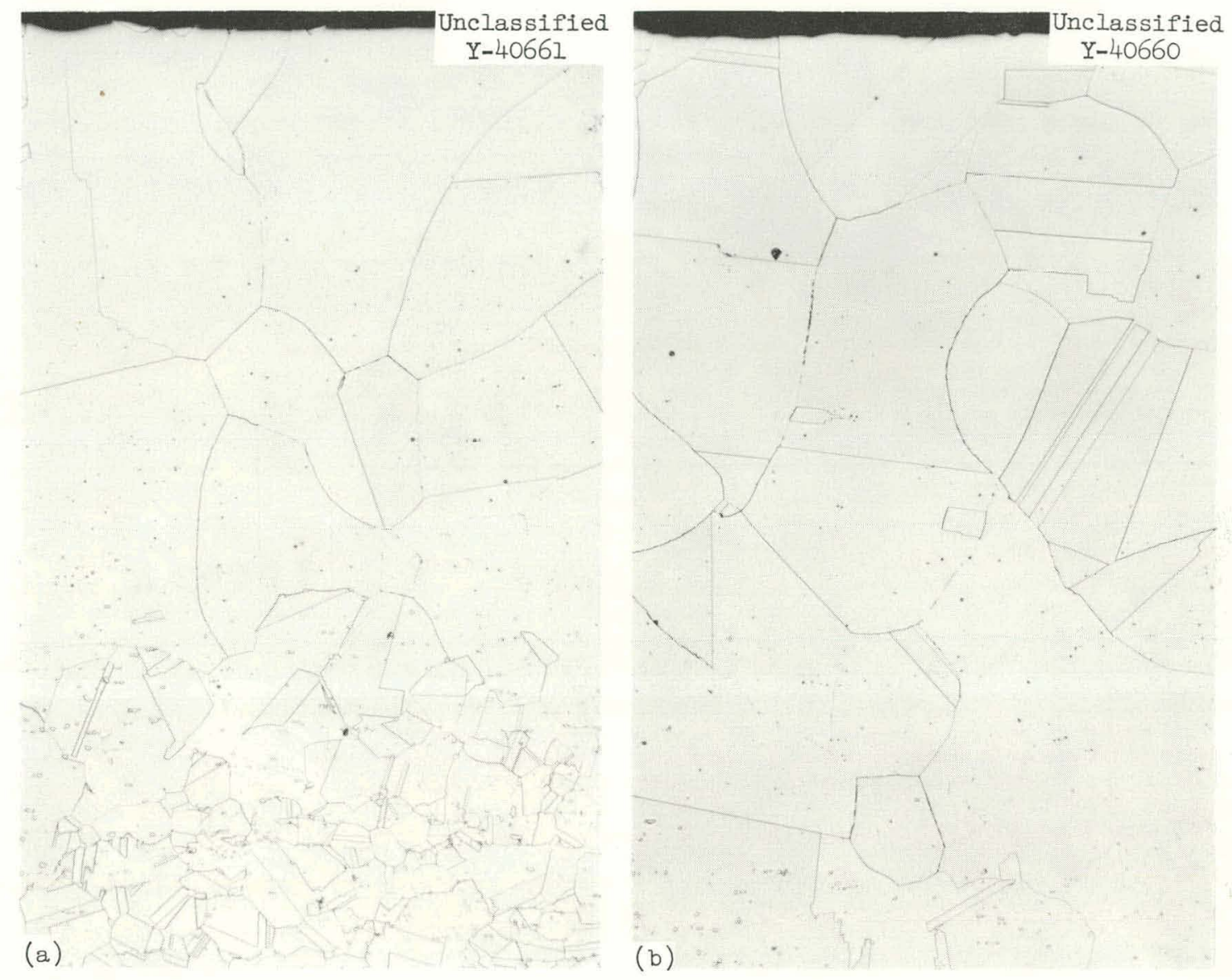

Figure 21. Austenitic stainless steel-0.128 weight per cent boron alloy heat treated for sixteen hours at $1135^{\circ} \mathrm{C}$ in hydrogen. (a) Maximum deboronized depth and (b) minimum deboronized depth. Etchant: Glyceria regia. 200X. 
exposed to the flowing hydrogen atmosphere. Both values are listed in Table XVIII.

The maximum depths of the deboronized layers, $\zeta$, are compared to $\zeta$ values computed assuming that solid-state diffusion is the ratecontrolling deboronization mechanism in Figure 22. Considering the uncertainties inherent in both the measured and calculated $\zeta$ values, the two are in agreement confirming that the rate of deboronization is controlled by the solid-state diffusion of boron. The calculations were based upon a boron concentration of zero at the metal-gas interface. To account for the smaller deboronized layer associated with the sample side resting on the boat during heat treatment and to be consistent with the diffusion hypothesis, the surface boron concentration there must have been appreciably greater than zero. Therefore, an appreciable partial pressure of the boron-hydrogen reaction product, homeostatic with the sample surface, must have been generated in the relatively static volume of gas between the specimen and boat.

Deboronization of boron-bearing stainless steel was demonstrated to be independent of heat-treating atmosphere, providing an alternate reaction involving boron and corresponding reaction product escape route are available. Alloy coupons were heat treated in wet (15,000 parts per million $\mathrm{H}_{2} \mathrm{O}$ ) helium for four hours at $1135^{\circ} \mathrm{C}$. The resultant microstructure of a heat-treated sample is illustrated in Figure 23. Three clearly defined areas are evident progressing inward from the sample-atmosphere interface: (1) an oxide layer, (2) a 
TABLE XVIII

MEASURED VALUES OF $\zeta$, THE DEPTH OF DEBORONIZED ZONE

\begin{tabular}{ccc}
\hline \multirow{2}{*}{$\begin{array}{c}\text { Deboronization } \\
\text { Time (hr) }\end{array}$} & \multicolumn{2}{c}{$\zeta, \mathrm{cm} \times 10^{3}$} \\
\cline { 2 - 3 } 1 & 12.3 & Minimum** \\
2 & 16.9 & 10.8 \\
4 & 28.3 & 13.1 \\
8 & 35.3 & 14.4 \\
16 & 51.0 & 23.1 \\
\hline
\end{tabular}

* Surface in contact with atmosphere.

${ }^{*}$ Surface in contact with sintering boat. 


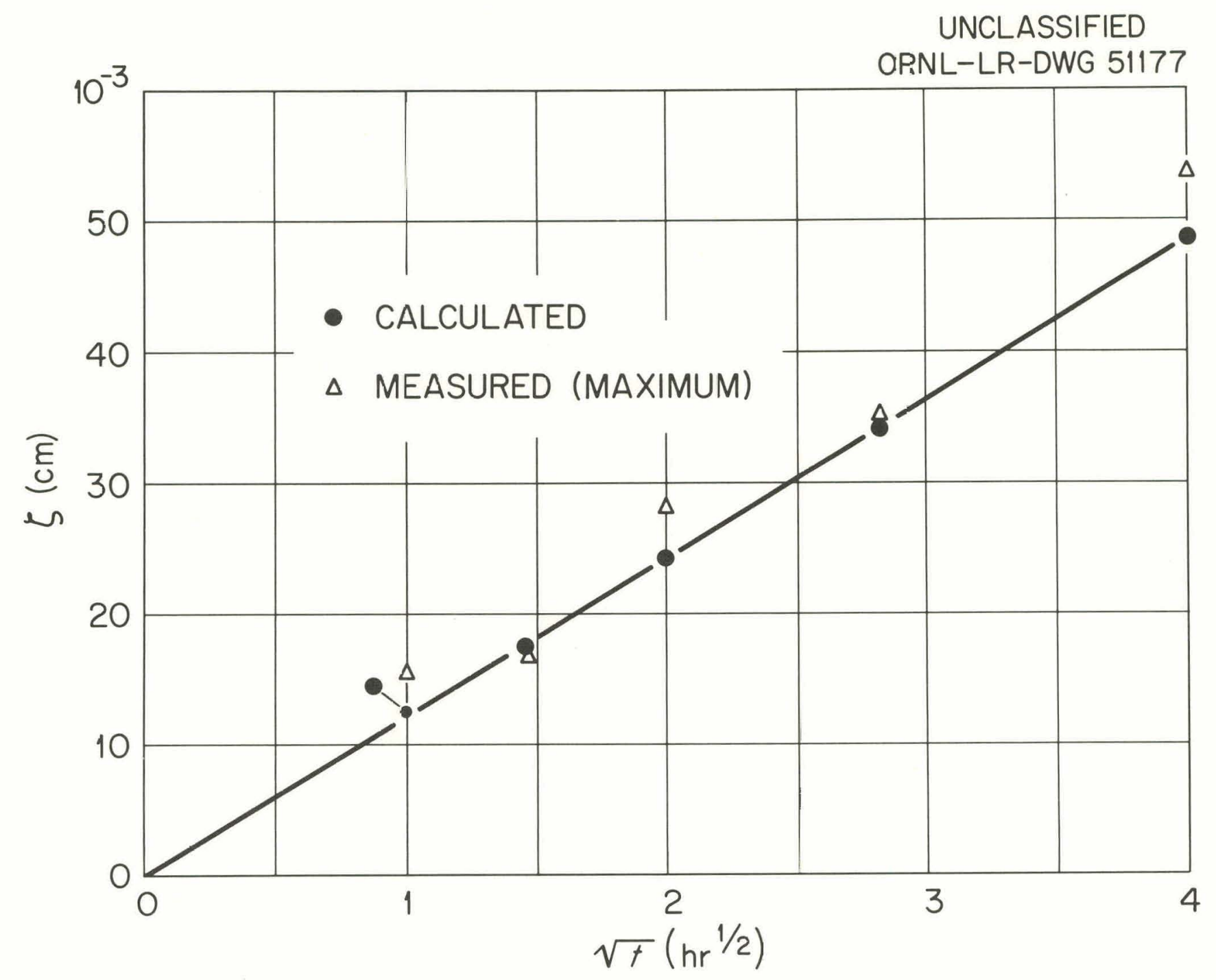

Figure 22. Deboronized layer thickness, $\zeta$, versus square root of time at $1135^{\circ} \mathrm{C}$ in hydrogen for samles of 0.128 weight per cent boron-stainless steel alloy. 


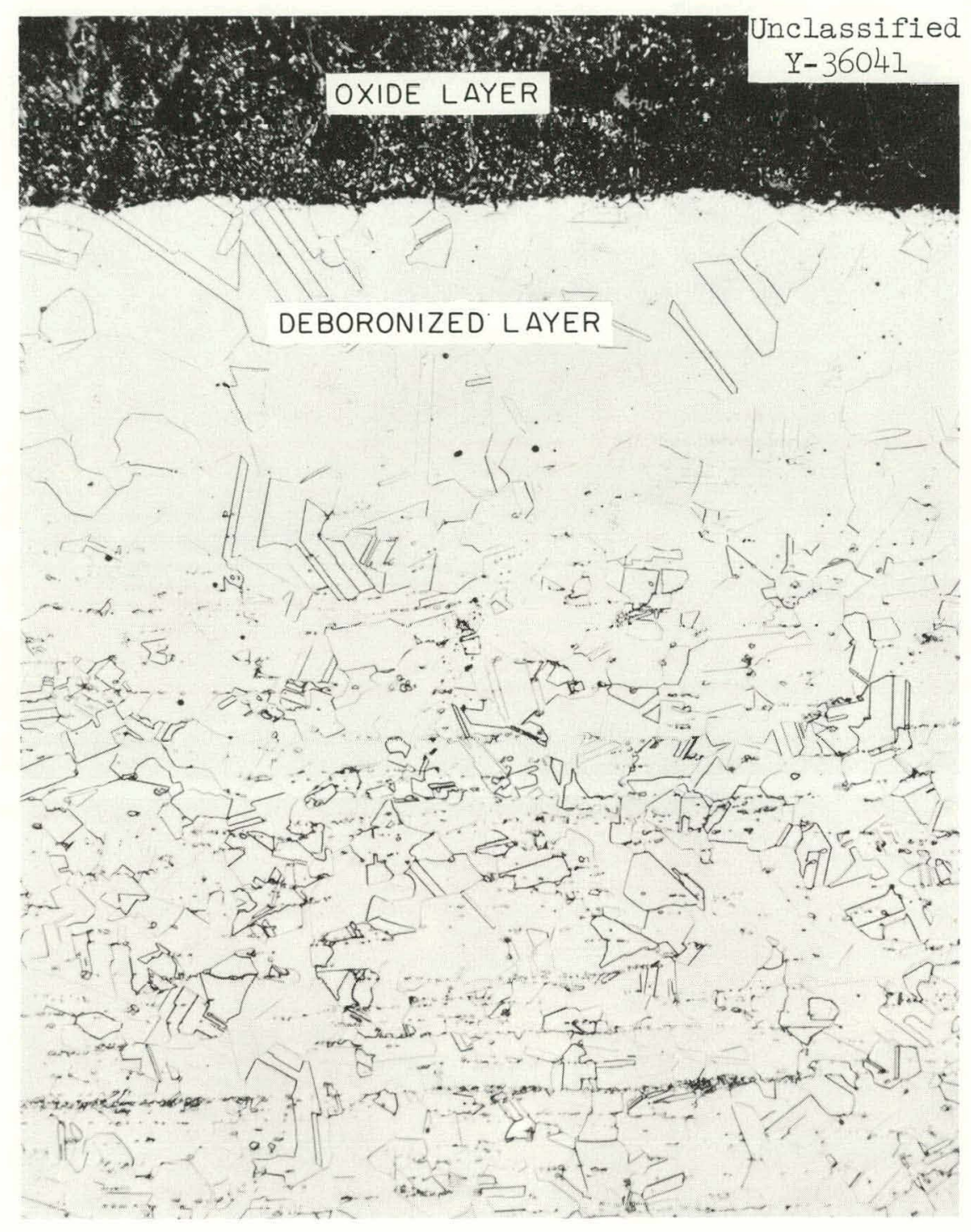

Figure 23. Metallographic section perpendicular to the surface of a sample deboronized in wet (15,000 parts per million) helium at $1135^{\circ} \mathrm{C}$ for four hours. The uppermost layer is an oxide skin, followed by a single-phase austenitic stainless steel deboronized layer and, finally, the originally two-phase metal. Etchant: Glyceria regia. 200X. 
single-phase deboronized layer, and (3) a two-phase central core of borides dispersed throughout an austenitic matrix. The oxide layer, itself, is trilayer as illustrated in Figure 24.

The maximum depth of the metallic layer, $\zeta$, was 0.023 centimeter, 0.005 centimeter less than its hydrogen deboronized counterpart. The reduction is probably due to the diffusion barrier imposed by the oxide skin and to conversion of the metal into the oxide. 


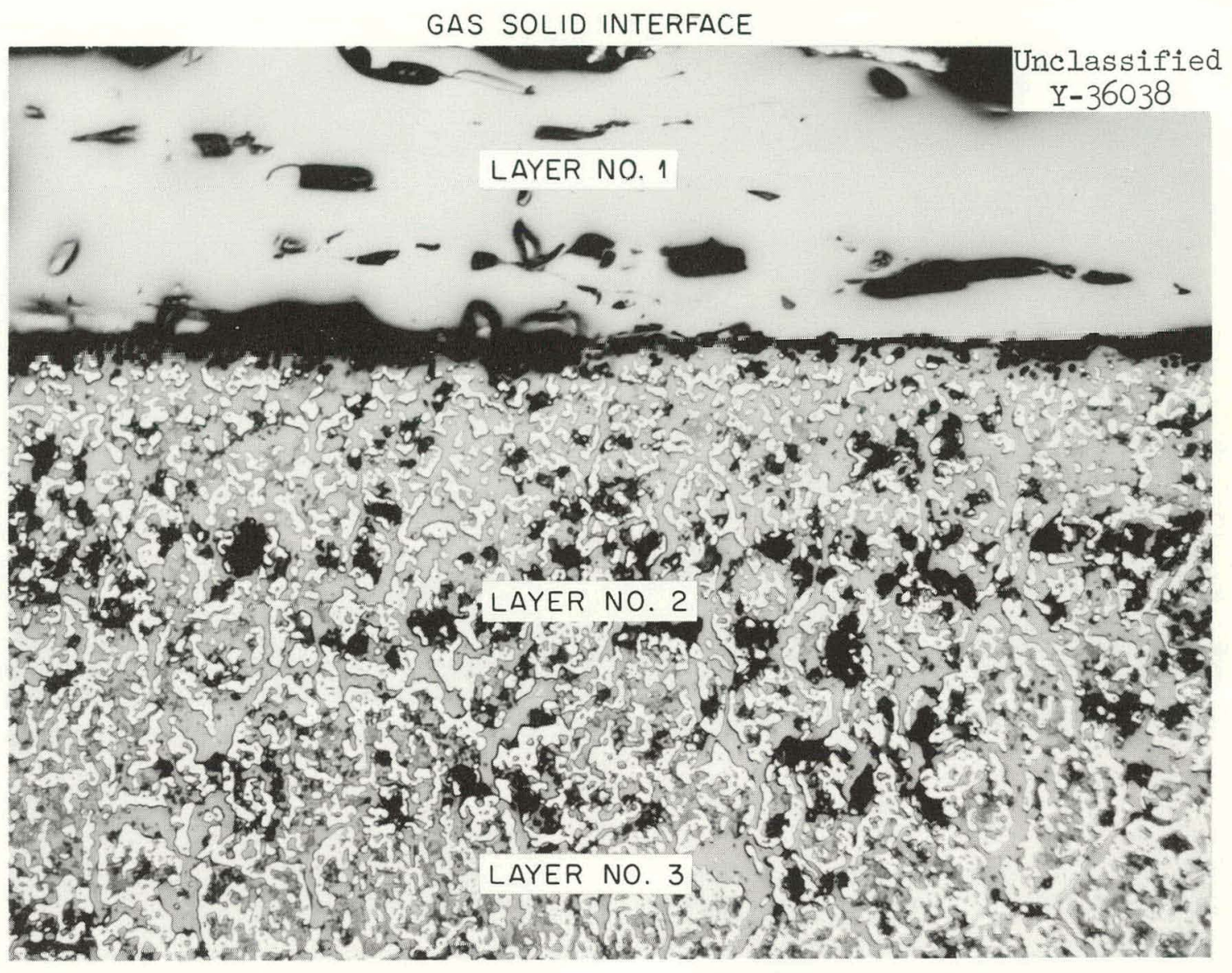

Figure 24. Structure of the oxide layer resulting from the deboronization of boronated stainless steel in wet (15,000 parts per million $\mathrm{H}_{2} \mathrm{O}$ ) helium. The first layer in contact with the gas sample interface is single phase. The next is a three-phase mixture of a gray matrix surrounding well defined white areas and some poorly defined dark phase. As the metal surface is approached, the disappearance of the dark phase is accompanied by an increase of the white. As polished. 500X. 
CHAPTERR VI

CONCLUSIONS

I. BORON LOSS FROM POWDER COMPACTS CONTAINING FIVE WEIGHT PER CENT BORON HEAT TREATED AT $1135^{\circ} \mathrm{C}$

1. Compacts containing a matrix of elemental iron, nickel, or cilicon dn not, experlenve significant boron losses when heat treated at $1135^{\circ} \mathrm{C}$ in either vacuum or high-purity argon.

2. The mechanism of boron loss from compacts containing a metal oxide matrix when heat treated in both vacuum and argon environments is:

$\frac{3}{\mathrm{y}} \mathrm{M}_{\mathrm{x}} \mathrm{O}+2 \mathrm{~B} \rightarrow \mathrm{B}_{2} \mathrm{O}_{3}(l)+\frac{3 \mathrm{x}}{\mathrm{y}} \mathrm{M}$

$\mathrm{B}_{2} \mathrm{O}_{3}(l) \rightarrow \mathrm{B}_{2} \mathrm{O}_{3}(\mathrm{~g})$

where $M$ is a metal cation. The loss, itself, is due lo the vaporization of boron sesquioxide. The rate of vaporization was greatest in the vacuum environment.

3. The magnitude of the boron loss experienced by samples containing a metal oxide matrix during heut treatmont in any environment is controlled by the structure of the sample rather than by the availability of reactants. In general, the rate of boron loss is governed by either gaseous or solid-state diffusion.

4. Samples having either a pure metal or metal oxide matrix experience a significant boron loss in one and one-fourth hours when 
heat treated in helium saturated with water vapor at $20^{\circ} \mathrm{C}$. The predominant mechanism of the loss is the oxidation of the boron to boron sesquioxide (either by the reduction of water vapor or internally contained metal oxide) and its subsequent volatilization.

5. Metal- or metal oxide-base compacts heat treated for one and one-fourth hours in hydrogen, containing less than 7, 15, or 460 parts per million $\mathrm{H}_{2} \mathrm{O}$, experience significant boron losses. The magnitude of the loss experienced by a given material combination is insensitive to the variations of the moisture content of the heat-treating atmosphere. It must therefore be presumed that a direct synthesis of hydrogen and boron occurs to form a volatile boron hydride.

\section{BORON LOSS ITROM BORON-STAINLESS STEELL ALIOYS}

1. The boron loss describes a parabolic relationship with time from five-gram compacts of 0.25 weight per cent boron-stainless steel alloy powder (master alloy), sintered at $1135^{\circ} \mathrm{C}$ in hydrogen of various water vapor contents. However, after two to seven hours of heat. treatment as dictated by the water content of the heat-treating environment, the loss rate decreases abruptly to a value considerably less than would be predicted by an extrapolation of the parabolic relationship.

2. The total fractional boron depletion for master alloy compacts at any given time is insensitive to hydrogen flow rate and water content between the limits of 20 to 40 cubic feet per hour and 100 to 460 parts per million $\mathrm{H}_{2} \mathrm{O}$, respectively. 
3. The total fractional boron depletion as a function of time from master alloy compacts heat treated at $1135^{\circ} \mathrm{C}$ in hydrogen, containing either 1, 100, or 460 parts per million water vapor, describes equivalent parabolic relationships for times up to two hours.

4. The rate of deboronization of the compacts heat treated in hydrogen of one part per million $\mathrm{H}_{2} \mathrm{O}$ asymptotically approaches a constant value after about two hours of heat treatment. The same rate is approached by the two series heat treated in wetter hydrogen, 100 and 460 parts per million $\mathrm{II}_{2} \mathrm{O}$, after approximately seven hours of heat treatment.

5. The amount and rate of compact sintering significantly decrease when the water content of the sintering atmosphere, hydrogen, is increased from 1 to 460 parts per million.

6. The deboronization rate of master alloy compacts is inversely proportional to the sintering rate:

7. The true rate of boron loss from master alloy compacts is controlled by the rate of diffusion of gaseous reactants into and reaction products out of the sample. The environmental variations influence the magnitude and rate of loss of boron only as they affect the rate of compact sintering.

Correspondingly, sintering affects the size and number of surface-connected channels present in the compacts through which the reactants diffuse. 
8. In hydrogen (less than 15 parts per million $\mathrm{H}_{2} \mathrm{O}$ ) and helium (15,000 parts per million $\mathrm{H}_{2} \mathrm{O}$ ) the rate of deboronization at $1135^{\circ} \mathrm{C}$ of wrought samples of 0.128 weight per cent boron-stainless steel alloy is controlled by the rate of solid-state diffusion of boron from the sample interior to the sample heat-treating atmosphere interface. 


\section{PAGES 86 to 87 WERE INTENTIONALLY LEFT BLANK}




\section{APP ENDIX I}

\section{CALCULATION OF BORON LOSS FROM A PLATE-TYPE SPECIMEN}

Consider a sheet specimen of boron-stainless steel alloy of surface area including sides, A, thickness, $d$, volume, $V$, and of original boron concentration, $\mathrm{C}_{\mathrm{O}}$. Assume that $\mathrm{C}_{\mathrm{O}} \gg \mathrm{C}_{I I, I}$ and $\mathrm{C}_{0} \cong \mathrm{C}_{\text {I, II }}$ (Figure 5a, page 18).

Then, neglecting edge effects, the boron lost, $\triangle \mathrm{B}$, would be

$\Delta \mathrm{B}=\zeta \mathrm{C}_{0} \mathrm{~A}$

where $\zeta$ is the depth of deboronized zone. The fractional boron depletion, $f_{d}=\frac{\triangle B}{C_{O} V}=\frac{\zeta A}{V}$

Substituting equation 4, page 17, into the above $f_{\mathrm{d}}=2 \gamma \sqrt{\mathrm{Dt}} \frac{\mathrm{A}}{\mathrm{V}}$. 


$$
\begin{aligned}
& 2 \mathrm{~B}(\mathrm{~s})+3 \mathrm{H}_{2} \mathrm{O}(\mathrm{g}) \leftrightharpoons \mathrm{B}_{2} \mathrm{O}_{3}(\mathrm{l})+3 \mathrm{H}_{2}(\mathrm{~g}) \\
& \Delta F_{\mathrm{R}}^{\circ}=\Delta F_{\mathrm{B}_{2} \mathrm{O}_{3}}^{\circ}-3 \Delta \mathrm{F}_{\mathrm{H}_{2}}^{\circ} \mathrm{O} \\
& \Delta F_{R}^{\circ}\left(1400^{\circ} \mathrm{K}\right)=-102.8 \mathrm{kcal}
\end{aligned}
$$

$\Delta F^{\circ}=-R T$ en $K=-2.303 R T \log _{10} \frac{\mathrm{A}_{2} \mathrm{O}_{3} \mathrm{f}_{2}^{3}}{\mathrm{f}_{\mathrm{H}_{2} \mathrm{O}}^{3}}$

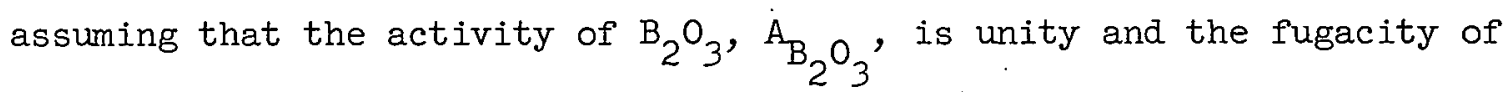
hydrogen and water vapor equals their respective partial pressure:

$\Delta F^{\circ}\left(1400^{\circ} \mathrm{K}\right)=-102.8 \mathrm{kcal}=-2.303\left(1.99 \frac{\mathrm{cal}}{\operatorname{mole}^{\circ} \mathrm{K}}\right)\left(1,00^{\circ} \mathrm{K}\right) \log _{10} \frac{\mathrm{p}_{\mathrm{H}_{2}}^{3}}{\mathrm{p}_{\mathrm{H}_{2} \mathrm{O}}^{3}}$

$\frac{\mathrm{p}_{\mathrm{H}_{2}}}{\mathrm{p}_{\mathrm{H}_{2} \mathrm{O}}}=1.1 \times 10^{6}$.

However, experimentally, $\mathrm{p}_{\mathrm{H}_{2} \mathrm{O}} \cong 18.8$ millimeters of mercury. Therefore, at equilibrium $\mathrm{p}_{\mathrm{H}_{2}}=20.7 \times 10^{6}$ millimeters of mercury, an impossible situation in the experiment. Thus, the conversion of boron to $\mathrm{B}_{2} \mathrm{O}_{3}$ can proceed to completion in a dynamic system. 
BORON LOSSES FROM 5-GRAM COMPACTS OF 0.25 WETGHT PER CENT BORON-STAINLESS STEEL ALLOY SINTERED IN HYDROGEN AT $1135^{\circ} \mathrm{C}$

\begin{tabular}{|c|c|c|c|c|}
\hline Sample & $\begin{array}{l}\text { Heat Treatment } \\
\text { Time }(\mathrm{hr})\end{array}$ & $\begin{array}{l}\text { Water Content } \\
\text { (ppm) }\end{array}$ & $\begin{array}{l}\text { Flow Rate } \\
\text { (CFH, STP ) }\end{array}$ & $\begin{array}{c}\text { Boron Loss, } \\
\triangle B(\mathrm{mg})\end{array}$ \\
\hline E 189 & $1 / 2$ & 460 & 40 & 3.1 \\
\hline E 190 & $1 / 2$ & 460 & 40 & 3.7 \\
\hline E 191 & $1 / 2$ & 460 & 40 & 2.7 \\
\hline E 192 & $11 / 4$ & 460 & 40 & 4.5 \\
\hline E 193 & $11 / 4$ & 460 & 40 & 4.4 \\
\hline E 195 & 2 & 460 & 40 & 6.1 \\
\hline E 196 & 2 & 460 & 40 & 5.9 \\
\hline E 198 & 4 & 460 & 40 & 7.8 \\
\hline E 199 & 14 & 60 & 40 & 7.7 \\
\hline E 200 & 4 & 460 & 40 & 7.8 \\
\hline E 201 & 8 & 160 & 40 & 10.2 \\
\hline E 202 & 8 & 460 & 40 & 10.2 \\
\hline E 203 & 8 & 460 & 40 & 10.1 \\
\hline E 260 & 16 & 460 & 40 & 11.8 \\
\hline E 261 & 16 & 1,60 & 4.0 & 11.9 \\
\hline E 262 & 16 & 460 & 40 & 12.1 \\
\hline E 212 & $1 / 2$ & 100 & 20 & 2.8 \\
\hline E 213 & $1 / 2$ & 100 & 20 & 3.0 \\
\hline E 204 & 1 & 100 & 20 & 3.4 \\
\hline $\mathrm{E} 205$ & $\overline{1}$ & 100 & 20 & 3.3 \\
\hline E 206 & 2 & 100 & 20 & 5.4 \\
\hline E 207 & 2 & 100 & 20 & 5.5 \\
\hline E 208 & 2 & 100 & 20 & 5.8 \\
\hline E 281 & 8 & 100 & 20 & 9.6 \\
\hline E 282 & 8 & 100 & 20 & 9.4 \\
\hline E 283 & 8 & 100 & 20 & 9.0 \\
\hline
\end{tabular}


APPENDIX III (continued)

\begin{tabular}{|c|c|c|c|c|}
\hline Sample & $\begin{array}{l}\text { Heat Treatment } \\
\text { Time (hr) }\end{array}$ & $\begin{array}{c}\text { Water Content } \\
(\mathrm{ppm})\end{array}$ & $\begin{array}{l}\text { Flow Rate } \\
\text { (CFH, STP) }\end{array}$ & $\begin{array}{c}\text { Boron Loss, } \\
\triangle B \text { (mg) }\end{array}$ \\
\hline E 248 & 1 & $\sim 1$ & 20 & 4.5 \\
\hline E 249 & 1 & $\sim 1$ & 20 & 4.0 \\
\hline E 250 & 1 & $\sim \overline{1}$ & 20 & 3.2 \\
\hline E 294 & 2 & $\sim 1$ & 20 & 4.8 \\
\hline E 295 & 2 & $\sim 1$ & 20 & 5.2 \\
\hline E 254 & 4 & $\sim 1$ & 20 & 5.9 \\
\hline E 255 & 4 & $\sim 1$ & 20 & 5.8 \\
\hline E 256 & 4 & $\sim 1$ & 20 & 5.9 \\
\hline E 257 & 8 & $\sim 1$ & 20 & 7.1 \\
\hline b 258 & 8 & $\sim 1$ & 20 & 6.9 \\
\hline E 259 & 8 & $\sim 1$ & 20 & 6.7 \\
\hline E 263 & $1 / 4$ & 4.60 & 20 & 1.7 \\
\hline E 264 & $1 / 4$ & 460 & 20 & 1.6 \\
\hline E 265 & $1 / 4$ & 460 & 20 & 1.8 \\
\hline E 266 & $1 / 2$ & 460 & 20 & 2.4 \\
\hline E 267 & $1 / 2$ & 460 & 20 & 2.8 \\
\hline E 268 & $1 / 2$ & 460 & 2.0 & 2.9 \\
\hline E 269 & $3 / 4$ & 460 & 20 & 2.7 \\
\hline E 270 & $3 / 4$ & 460 & 20 & 2.9 \\
\hline E 271 & $3 / 4$ & 460 & 20 & 3.3 \\
\hline E 278 & 2 & 460 & 20 & 7.2 \\
\hline E 279 & 2 & 460 & 20 & 7.4 \\
\hline E 280 & 2 & 460 & 20 & -7.8 \\
\hline
\end{tabular}


The rate of fractional boron depletion from a spheroid of a single-phase alloy assuming an infinite sink for the boron at the sample surface is

$\Gamma_{d}=1-\frac{\sigma}{\pi^{2}} \sum_{m=1}^{\infty} \frac{1}{m^{2}} \exp \left[-\operatorname{mint} / r^{2}\right]($ ret $3 j)$

where

$$
\begin{aligned}
& \mathrm{D}=\text { diffusion coefficient, } \\
& t=\text { diffusion time, and } \\
& r=\text { radius of the spherical particle. }
\end{aligned}
$$

The equivalent radius of spheres in a powder compact of surface area, $S$, is given by

$r=\frac{3}{S \rho}$

where $\rho=$ the powder density.

Combining equations 22 and 23 :

$f_{\dot{\alpha}}=1-\frac{\sigma}{\pi^{2}} \sum_{m=1}^{\infty} \frac{1}{m^{2}} \exp \left[-\frac{m \pi D+s^{2} \rho^{2}}{9}\right]$.

Expanding to $\mathrm{m}=2$ and substituting the diffusion data of Busby et al. and $s=170 \mathrm{~cm}^{2} / \mathrm{g}$ (corresponds to the surface area of five-gram alloy compacts sintered in vacuum for six hours at $1135^{\circ} \mathrm{C}$ ) then: 
$f_{d}(t=1 \mathrm{sec})=0.64$.

The boron depletion rate per second from such a compact can be described by differentiating equation 24 with respect of time.

$\frac{d f_{d}}{d t}=\frac{2 D S^{2} \rho^{2}}{3 \pi} \sum_{m=1}^{\infty} \frac{1}{m} \exp \left[-\frac{m \pi D S^{2} \rho^{2} t}{9}\right]$.

Equation 26 holds only at the inception of deboronization since the actual material system is two phase, and therefore, $\frac{d f}{d t}$ would be constant until all the boron-rich intermetallic compound had dissolved, presuming its dissolution rate fast enough. Expanding equation 26 to $m=2$ and solving at $t=1 \mathrm{sec}$ yields

$\frac{d f}{d t}(t=1.0 . \mathrm{sec})=0.38 \mathrm{sec}^{-1}$. 
THIS PAGE

WAS INTENTIONALLY

LEFT BLANK 
I.TST OF REFERENCES 


\section{LIST OF REFERENCES}

1. Waugh, R. C., Unpublished work at the Oak Ridge National Laboratory.

2. Cunningham, J. E., et al., Specifications and Fabrication

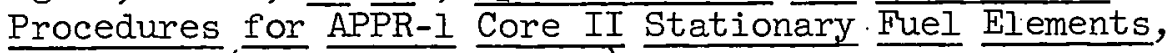
ORNL-2649 (February 11, 1959).

3. Cherubini, J. H. , Army Package Power Reactor Project Annual Progress Report for Period Ending January 31, 1960, ORNL-2907, pp. 7-10 (March 25, 1960).

4. Grossman, M. A., "Hardenability Calculated from Chemical Composition," Trans. A IMT, Irop dill Jbeel Div., 150, $227-259(1942)$.

5. Dean, R. S., and Silke日, B., Boron in Iron and Steel, Bureau of Mines Publication No. IC-7363 (September, 1956).

6. Thum, E. E: (ed.), Boron Steel, American Society for Metals, 2d ed. , 1953.

7. Middleham, T. H., Rait, J. R., and Colbeck, E. W., "High Boron Alloy Steels," J. Iron and Steel Inst. , 34, 1-14 (September, 1957).

8. Watanabe, H. T., and Schaffiret, W. O., Radiation Damage Studies of Boron-Stainless Steel, IDO-16483.(September 18, 1958).

9. Hildebrand, R. D., and Volovage, W. D., Tensile Properties of Stainless Steel, Zirconium, and Titanium Alloyed with Boron, KAPL-M-WDV-2 (December 7, 1355).

10. Prus, I. B., et al., Metallurgy Information Meeting, Ames Laboratory, Towa State College, May 2,3 and 4 , 1956, TID-7526(Part 2a) pp. 198-207 (March, 1957). (Classified)

11. Parke, R. M., "Boron Iron Constitution Diagram," Metals Handbook, p. 1175, Cleveland Chapter of the American Society for Metals, 1948.

12. Busby, P. E., Warga, M. E., and Wells, C., "Diffusion and Solubility of Boron in Iron and Steel," J. Metals, 1463-1468 (November, 1953).

13. Tscheschewsky, N. , "The Case Hardening of Iron by Boron," J. Iron and Steel Inst. , 95, 185-187 (1917). 
14. Cambell, T. P., and Fay, H., "The Case Hardening of Steel by Boron and Nitrogen," Ind. Eng. Chem., 16, 719-7.23 (1924).

15. Diggs, T. G., Irish, C. R., and Canvile, N. L., "Effect of Boron on the Hardenability of High-Purity Alloys and Commercial Steels," J. Research Nat. Bur. Standards, 41, 545-574 (1948).

16. Shyne, J. C. , and Morgan, E. R. , "Deboronization of Steels," Metal Progr. , 65, 88-90 (1954).

1.7. Coughl.in, T. P., Contributions to the Data on Theoretical Metallurgy, Nat. Bur. Standards Bulletin 542 (1954).

18. Evans, W. H., Wagmun, D. D., and Prosen, E. J., Thermodynamic Properties of Some Boron Compounds, Nat. Bur. Standards Report No. $494 \overline{3}$ (August $3 \overline{1}, 1956)$.

19. Margrave, J. I., and Soulen, J. R., Vaporization Studies of Boric Oxide, CCC-1024-TR-86 (January 14, 1955).

20. Evans, W. H., Wagmun, D. D., and Prosen, E. J., The Vapor Pressures of Some Boron Compounds, Nat. Bur. Standards Report No. 5663 (December 3, 1957).

21. Rizzo, H. F., et al., "Oxidation of Boron at Temperatures Between $4 \overline{00}$ and $1300^{\circ} \mathrm{C}$ in Air, " Conference on Boron, U. S. Army Signal Research and Development Laboratory, Ft. Monmouth, New Jersey, September 18-19, 1959.

22. Glasstone, S., Textbook of Physical Chemistry, Van Nostrand, New York, 1940.

23. Margrave, J. L., et al. , Structure and Thermodynamic Properties of High-Temperature Gaseous species in the $\mathrm{B}_{2} \mathrm{O}_{3}-\overline{\mathrm{H}}_{2} \mathrm{O}$ - System, $\mathrm{CC}-1024-\mathrm{TR}-231$ (1957).

24. Kanda, F. A., et al., J. Am. Chem. Soc., 78, 1509 (1956).

25. Diborane, Callery Chemical Company Technical Bulletin C-020 (March 15, 1958).

26. Newkirk, A. E., and Hurd, D. T., "The Direct Synthesis of Boron Hydrides," J. Am. Chem. Soc. , 77, 241 (1955).

27. Belle, J., and Benington, F., MCC-1023-TR-134 (May 27, 1955). (Classified) 
28. Brown, C. A., and Hashman, J. F., MCC-1023-TR-54 (June, 1954). (Classified)

29. Jost, W., Diffusion in Solids, Liquids, and Gases, pp. 72-73, Academic Press, New York, 1952.

30. Thomas, G. B., Jr., Calculus and Analytical Geometry, p. 226, Addison-Wesley, Reading, Massachusetts, 1953.

31. Rosenberg, A. J., J. Am. Chem. Soc., 78, 2929 (1956).

32. Cherubini, J. H., Metallurgy Division Annual Progress Report for Pcriod Ending Ootobar $10,19,58,0 \overline{B N \pi}=2632$, n. 140 (December I, 1958).

33. Cherubini, J. H., Metallurgy Division Annual Progress Report for Period Ending. September 1 1, 1959, ORNL-28 $8 \overline{39}$, p. 240 (November 16, 1959).

34. Chang, W. H., "A Dew. Point-Temperature Diagram for Metal-Metal. Oxide Equilibria in Hydrogen Atmosphere, " Welding J. , 35, 622s (December, 1956).

35. Crank; J.., The Mathematics of Diffusion, Oxford Clarendon Press, . New Jersey, 1956. 


\author{
ORNL-314I \\ Metals, Ceramics, and Materials \\ TID-4500 (16th ed.)
}

\title{
DISTRIBUTION
}

1. Biology Library

2-3. Central Research Library

4. Reactor Division Library

5. ORNL Y-12 Technical Library Document Reference Section

6-25. Laboratory Records Department

26. Laboratory Records (RC)

2.7. G. M. Adamson, Jr.

28. R. J. Beaver

29. D. S. Billington

30. A. L. Boch

31. E. G. Bohlmann

32. B. S. Borie

33. D. T. Bourgette

34. R. B. Briggs

35. C. E. Center

36. R. A. Charpie

37-42. J. H. Cherubini

43. R. S. Cockreham

44. E. Cohn

45. F. L. Culler

46. J. E. Cunningham

4\%. D. A. Douglas

48. J. H. Erwin

49. J. H Frye, Jr.

50. A. Goldman

51. R. J. Gray .

52. W. R. Grimes

53. J. P. Hammond

54. C. S. Harrill

55-59. M. R. Hill

60. R. M. Hill

61. A. Hollaender

62. A. S. Householder

63. R. G. Jordan $(Y-12)$

64. 'W. H. Jordan

65. C. P. Keim

66. M. T. Kelley
67. W. R. Laing

68. J. T. Lamartine

69. J. A. Lane

70. R. S. Livingston

71. H. G. MacPherson

72. W. D. Manly

73. M. M. Martin

74. C. J. McHargue

75. A. J. Miller

76. E. C. Miller

77. C. S. Morgan

78. K. Z. Morgar

79. J. P. Murray (K-25)

80. M. L. Nelson

81. P. Patriarca

82. D. Phillips

83. S. A. Rabin

84. F. M. Reyling

85. T. K. Roche

86. H. W. Savage

87. H. E. Seagren

88. E. D. Shipley

89. M. J. Skinner

90. G. M. Slaughter

91. C. O. Smith

92. A. H. Bnell

93. J. A. Swartout

94. E. H. Taylor

95-96. W. C. Thurber

97. T. D. Watts

98. A. M. Weinberg

99. J. C. Wilson

100. C. E. Winters

101. A. A. Burr (consultant)

102. J. H. Koenig (consultant)

103. C. S. Smith (consultant)

104. R. Smoluchowski (consultant)

105. H. A. Wilhelm (consultant) 
EXTERNAL DISTRRIBUTION

106-109. Alco Products, Inc., Schenectady, New York

(Attn.: K. Kasschau)

110. D. E. Baker, GE Hanford

11l-112. Battelle Memorial Institute, Columbus, Ohio

(Attn.: S. Paprocki)

113-114. Combustion Engineering, Inc., Idaho Falls, Idaho

(Attn.: W. B. Allred)

115-116. . D. Cope, ORO

117-118. District Engineer, Alaska District, U. S. Army Corps of Engineers, Anchorage, Alaska

119-120. District Engineer, Eastern Ocean District, U. S. Army Corps of Engineers, New York, N. Y.

121-130. Division of Reactor Development, AEC, Washington (Attn. : Col. Henry C. Schrader)

131. Ersel Evans, GE Hanford

132. J. I. Gregg, Cornell University

133-134. New York Operations Office

(Attn.: Chief, Army Reactors Branch)

135-136. Office Chief of Engineers, Washington, D. C. (Attn.: Chief, Nuclear Power Division)

137. H. M. Roth, ORO

138. J. Simmons, AEC, Washington

139-141. E. E. Stansbury, University of Tennessee

142. Donald Stevens, AEC, Washington

143-144. The Martin Company, Baltimore, Maryland

(Attn.: J. F. O'Brien)

145-148. U. S. Army Engineer Research and Development Laboratories, Fort Belvoir, Va. (Attn. : Chief, Nuclear Power Field Office)

149-725. Given distribution as shown in TID-4500 (16th ed.) under. Metals, Ceramics, and Materials Category (75 copies-OTS) 